\title{
Water and Martian habitability: Results of an integrative study of water related processes on Mars in context with an interdisciplinary Helmholtz research alliance "Planetary Evolution and Life"
}

\author{
R. Jaumann ${ }^{\mathrm{a}, \mathrm{b}, *}$, D. Tirsch ${ }^{\mathrm{a}}, \mathrm{E}$. Hauber ${ }^{\mathrm{a}}, \mathrm{G}$. Erkeling ${ }^{\mathrm{c}}$, H. Hiesinger ${ }^{\mathrm{c}}$, L. Le Deit ${ }^{\mathrm{a}, \mathrm{d}}$, M. Sowe $^{\mathrm{b}}$,
} S. Adeli ${ }^{\text {a }}$, A. Petau ${ }^{\text {a }}$, D. Reiss ${ }^{\text {c }}$

${ }^{\text {a }}$ DLR, Institute of Planetary Research, Berlin, Germany

${ }^{\mathrm{b}}$ Freie Universität Berlin, Institute of Geosciences, Berlin, Germany

${ }^{\mathrm{c}}$ Institut für Planetologie, Westfälische Wilhelms-Universität, Münster, Germany

${ }^{\mathrm{d}}$ Laboratoire de Planétologie et Géodynamique, UMR 6112, CNRS, Université de Nantes, Nantes, France

\section{A R T I C L E I N F O}

\section{Article history:}

Received 11 March 2013

Received in revised form

10 February 2014

Accepted 21 February 2014

Available online 5 March 2014

\section{Keywords:}

Mars

Habitability

Aqueous environment

Water-related

\begin{abstract}
A B S T R A C T
A study in context with the Helmholtz Alliance 'Planetary Evolution and Life' focused on the (temporary) existence of liquid water, and the likelihood that Mars has been or even is a habitable planet. Both geomorphological and mineralogical evidence point to the episodic availability of liquid water at the surface of Mars, and physical modeling and small-scale observations suggest that this is also true for more recent periods. Habitable conditions, however, were not uniform over space and time. Several key properties, such as the availability of standing bodies of water, surface runoff and the transportation of nutrients, were not constant, resulting in an inhomogeneous nature of the parameter space that needs to be considered in any habitability assessment. The planetary evolution of Mars led to environmental changes, which in turn affected its habitability potential. Similarly, considerable variations in climate due to latitudinal or elevation effects combined with a diverse surface geology caused distinctively different local conditions that influenced the planet's habitable potential.
\end{abstract}

(c) 2014 Elsevier Ltd. All rights reserved.

\section{Introduction}

Habitability is commonly understood as "the potential of an environment (past or present) to support life of any kind" (Steele et al., 2005) regardless whether life actually exists or has existed. It refers instead to environmental conditions that could support life. Thus it is essential to understand the geological context of such environmental conditions. Life as known from Earth requires energy sources, the nutrients $(\mathrm{C}, \mathrm{H}, \mathrm{O}, \mathrm{N}, \mathrm{P}, \mathrm{S})$ necessary for building structures and synthesizing catalysts, and access to geological environments in which biosynthesis and maintenance of biostructures are possible (e.g., Wald, 1964). A habitable planetary environment, regardless if past, present, or future, would have to be one of that features all of the above requirements. No life on other planets than Earth has been detected so far, and therefore it is not possible to determine what its overall environmental requirements are. Nevertheless, the one environmental factor that is almost universally accepted as necessary for life is at least episodic access to liquid $\mathrm{H}_{2} \mathrm{O}$. The availability of the above parameters through time is a

\footnotetext{
* Corresponding author.

E-mail address: ralf.jaumann@dlr.de (R. Jaumann).
}

function of the geologic evolution of a planet or moon. Therefore, the geological investigation of planetary systems, analogous to the Earth even in a weak sense, is the key to our understanding of the concept of habitability. This characterization includes geochemical and mineralogical knowledge of surface or near-surface rocks and soils, the nature of the atmosphere and climate, the type, intensity and rates of geological processes, and finally the history of water or other liquids all these factors are intimately related to planetary geology.

Water is an abundant compound in our galaxy, it can be found in many places, from cold dense molecular clouds to hot stellar atmospheres (e.g., Cernicharo and Crovisier, 2005). In our solar system, $\mathrm{H}_{2} \mathrm{O}$ is abundant on all planetary bodies and it exists in all phases - solid, gaseous and liquid - within a certain solar distance. The habitable zone, where liquid water can be present at the surface, changes with time dependent on the solar energy (e.g., Kasting et al., 1993) enabling not only Earth but also Mars to have liquid water stable on and near the surface for a certain time. Also, water as a liquid may exist almost independent of the input of stellar energy in oceans covered by ice shells as it is probably the case for the icy satellites of Jupiter (Schubert et al., 2004), which are located well outside the conventional habitable zone of the sun, driven by tidal dissipation and radiogenic energy. The $\mathrm{H}_{2} \mathrm{O}$ molecule is polar, keeping a small charge gradient between oxygen 
and hydrogen. Thus water acts as a solvent of materials with time. If other volatiles such as atmospheric $\mathrm{CO}_{2}$ are solved in water, it turns into a weak acid and enhances its weathering capability. Its dynamic viscosity makes it, even at low temperatures, in combination with gravity effectively mobile supporting the transportation of any material. Its thermal anomaly at low temperatures causes intense phase changes making $\mathrm{H}_{2} \mathrm{O}$ a mechanical destructor and allows ice to swim on water providing shelter for the liquid in thermally harsh environments. At higher temperatures it increases its mobility and its capability to carry solved gases. From a geological point of view, water is the ideal medium to alter, transport and displace surface and sub-surface material, and to carry the erosional and mobility forces needed to resurface planetary bodies on a global scale. This additionally requires a cycling process to distribute water all over the planet on the surface and in the sub-surface. A hydrological cycle via the atmosphere enables global distribution and recharging of reservoirs via precipitation, whereas hydrological cycling on the surface enables weathering. The regional recharging and cycling in the sub-surface via cracks and pore space enables chemical alteration of materials and coupling to internal thermal energy via hydrothermal processes.

The aqueous weathering, erosion, and sedimentation history of a surface is an expression of all processes correlated to the hydrosphere and their interactions with the atmosphere and the interior. Thus, the analysis of the surface geology provides insight into the climatic constraints that existed during the formation of surface features and this understanding provides the basis to assess the habitability of environments.

Besides Earth, the most logical place to look for habitability in the solar system, is Mars: It is the most Earth-like of all the other planetary bodies in terms of its geological surface record and the availability of liquid water at or near the surface throughout its evolution (Lasue et al., 2013). Moreover, solar energy, geothermal and chemical energy, as well as nutrients, are thought to be available on Mars. Hence, the analysis of the surface and nearsurface geology is more than just the direct observation and interpretation of landforms and surface composition. It can also indirectly validate or invalidate models of atmospheric evolution, of interior geophysical processes, and of impact probabilities.

A five years study in context with the Helmholtz Alliance 'Planetary Evolution and Life' focused on the (temporary) existence of liquid water, and its likelihood that Mars has been or even is a habitable planet. Both geomorphological and mineralogical evidences demonstrate that water was present on ancient Mars, and this may also be true for very recent periods. Thus, past habitable conditions on Mars are expected, but may have been variable over space and time.

\section{Concepts of the water-related history of Mars}

The history of water on Mars has been constantly revised and refined during the past decades. Landforms such as widespread valley networks, fluvial deposits and associated assemblages of hydrated clay minerals led researchers to propose the hypothesis that the Martian climate was considerably warm and wet during Noachian times (e.g., Sagan et al., 1973; Pollack et al., 1987; Squyres and Kasting, 1994; Jakosky and Phillips, 2001; Craddock and Howard, 2002; Malin and Edgett, 2003; Irwin et al., 2005b; Poulet et al., 2005a; Barnhart et al., 2009; Hoke and Hynek, 2009; Andrews-Hanna and Lewis, 2011). However, alternative studies give reason to suggest that the aqueous altered clay minerals do not necessarily imply intense surface weathering under humid conditions but could have also been formed by subsurface weathering associated to hydrothermal processes or groundwaterrelated weathering under cold and dry environmental conditions (e.g., Ehlmann et al., 2011, 2013). Also the existence of highly developed valley networks is not necessarily a surety for intense continuous rainfall. Erosion rates of valley networks imply that warm and wet conditions might only be met occasionally in recurring phases (e.g., Solomon et al., 2005; Carr and Head, 2010). Detailed analyses of diagnostic landforms propose an alternative view of the early climate to be cooler and drier with only sporadic and transient water-related events (e.g., McEwen et al., 2007; Christensen et al., 2008).

These observations and considerations led to the assumption that at the boundary between the Late Noachian and the Early Hesperian, environmental and climate conditions changed significantly and resulted in a transition towards a colder and dryer climate. The intensity of aqueous activity decreased throughout the Hesperian, including a transition from long-term and repeated precipitation-induced fluvial activity towards reduced, short-term, spatially isolated and groundwater-dominated fluvial erosion (e.g., Baker et al., 1992; Carr, 1995, 2012; Tanaka, 1997; Goldspiel and Squyres, 2000; Grant, 2000; Carr and Head, 2003; Harrison and Grimm, 2005; Jaumann et al., 2005, 2010; Solomon et al., 2005; Komatsu et al., 2009; Michalski et al., 2013 and references herein). At the end of the Hesperian, fluvial erosion had mostly ceased and volcanic, aeolian and glacial processes are interpreted to be dominant on Mars. The Early Amazonian was finally characterized most likely by a cold and dry climate that was similar to the conditions on recent Mars (e.g., Sagan et al., 1973; Mustard et al., 2001; Kreslavsky and Head, 2002; Head et al., 2004, 2005, 2006; Solomon et al., 2005; Fassett and Head, 2008b; Ivanov et al., 2012). However, Mars' climate and aqueous history, in particular the timing of the termination of fluvial activity and the transition from precipitation-induced toward groundwater-dominated erosion, is still subject to debate.

At current atmospheric conditions, liquid water and exposed water ice are metastable, or at least short-lived, on the surface of Mars. Today, the largest inventories of water on Mars are located at the poles, where huge masses of water ice are captured in the polar caps (e.g., Titus et al., 2003; Bibring et al., 2004). Near surface ice or ground ice has been supposed by geomorphological studies (e.g. Baker, 2001; Mouginot et al., 2012) and finally evidenced insitu by the Phoenix lander (e.g. Byrne et al., 2009; Keller et al., 2009; Markiewicz et al., 2009; Cull et al., 2010; Sizemore et al., 2012). However, there is ample geomorphological and mineralogical evidence for pervasive interaction of fluvial water with the Martian surface, resulting in diagnostic landforms, including largescale environments such as outflow channels, medium-scale environments such as valley networks, and local features such as paleolakes, alluvial fans, deltas and gullies. Distinct flow structures preserved on the surface indicate flow directions as well as morphometric parameters, such as channel width, depth, and slope, which permit estimating discharges and recurrence intervals (e.g., Irwin et al., 2005b, 2008; Jaumann et al., 2005, 2010; Fassett and Head, 2008a). Large outflow channels, spread over vast regions on the surface, are characterized by broad, deep channels, which emerge fully born from localized sources (Carr, 1979, 2012). They are supposed to be the result of the cataclysmic release of significant amounts of groundwater, probably triggered by a progressively thickening cryosphere or volcanic loading of confined aquifers (e.g., Carr, 1979; Baker, 2001; Wilson et al., 2004; Andrews-Hanna and Phillips, 2007; Musiol et al., 2011) and thus might indicate the existence of liquid water on the surface for short flooding periods. The activity of outflow channels was probably initiated in the Noachian with peak phases during Late Hesperian and Early Amazonian (e.g., Baker, 2001; Tanaka et al., 2005; Carr and Head, 2010; Neukum et al., 2010). Some smaller outflow channels were carved by cataclysmic spillover flooding as a consequence of paleolake outbursts. Those short-lived water occurrences can be caused by ground ice melting and rupture of 
the cryosphere, releasing water from the underground (Head et al., 2003b; Wilson and Head, 2004). Recent studies of outflow channels and inter-basin chasmata in the eastern Valles Marineris region provide geomorphologic and chronologic evidence for significant bedrock erosion initiated by catastrophic spillover by kilometer-deep bodies of water, which would have existed well after the global climate optimum of the Noachian (Warner et al., 2013).

Numerous valley networks dissect the surface of Mars; most of them are located in the southern highlands. The majority of their ages cluster around the Noachian-Hesperian boundary (Fassett and Head, 2008b). However, some fluvial networks imply activity phases during the Hesperian and even in Amazonian times, particularly at the flanks of volcano edifices (Gulick and Baker, 1990; Mangold et al., 2004; Fassett and Head, 2008b, 2011; Bouley et al., 2009, 2010). Dendritic valley networks develop, analogous to terrestrial features, under the influence of surface runoff as a consequence of precipitation (i.e. rain) or the melting of snow and/or ice deposits (e.g., Craddock and Howard, 2002; Carr and Head, 2003; Mangold et al., 2004; Irwin et al., 2005b; Fassett and Head, 2008a; Barnhart et al., 2009; Hoke and Hynek, 2009; Jaumann et al., 2010; Stepinski and Luo, 2010). Under constant delugestyle conditions, valley network formation requires about $10^{3}-10^{4}$ years (e.g., Moore et al., 2003; Jaumann et al., 2010) of fluvial activity, episodic and moderate condition modeling yields timescales of about $10^{5}-10^{6}$ years (Moore et al., 2003; Jaumann et al., 2005; Barnhart et al., 2009) or even $10^{5}-10^{7}$ (Hoke et al., 2011). Linear valley networks were probably formed by groundwater sapping (e.g., Sharp and Malin, 1975; Kochel and Howard, 1985; Malin and Carr, 1999; Carr and Malin, 2000; Goldspiel and Squyres, 2000; Harrison and Grimm, 2005; Jaumann et al., 2005, 2010). At their amphitheater-shaped valley heads, groundwater percolates from the subsurface and causes regressive erosion (seepage erosion) (Dunne, 1980). Gullies are further surface features that are supposed to be the result of, at least transient, liquid water. They were formerly supposed to result from groundwater seepage and surface runoff (Malin and Edgett, 2000a). Recent analyses suggest that they result from the melting of near surface ice or snow packs and develop in dependency of exposition and latitude (Costard et al., 2002; Christensen, 2003; Reiss et al., 2009; Kneissl et al., 2010; Raack et al., 2012). Paleolakes were identified in many topographic lows such as impact craters and valleys, preferably in the southern highlands (e.g., Cabrol and Grin, 1999; Di Achille et al., 2007; Fassett and Head, 2008a). They are often associated with deltas or fan-like deposits that are known to develop in standing water bodies attesting a, at least temporary, sustained presence of liquid water (e.g., Ori et al., 2000; Malin and Edgett, 2003; Fassett and Head, 2005; Fassett et al., 2007; Pondrelli et al., 2008; Di Achille and Hynek, 2010). It is still under debate, whether these paleolakes were essentially fed by precipitation and regionally connected groundwater aquifers under much warmer and wetter climate than current conditions (Fassett and Head, 2008b; Wray et al., 2011), and/or by liquid water remobilized from the cryosphere under cold and arid conditions (Cabrol and Grin, 2002), possibly later in the Martian history (Dehouck et al., 2010). The largest potential water reservoir proposed for Mars is a giant ocean that might have covered the plains of the northern lowlands. This hypothesis is mainly based on the smoothness of this terrain, in conjunction with the lack of impact craters, the identification of series of morphological features interpreted as shorelines, and the orientation of valley networks and deltas (e.g., Parker et al., 1989, 1993; Baker et al., 1991; Head et al., 1999; Clifford and Parker, 2001; Webb, 2004; Ghatan and Zimbelman, 2006; Di Achille and Hynek, 2010; Clifford et al., 2012; Mouginot et al., 2012; Parker and Calef, 2012). However, the existence of an ocean is one of the most debated uncertainties of Mars' aqueous evolution.

Since about a decade, mineralogical and chemical analyses from orbit and in situ investigations revealed that diverse hydrated minerals are widely distributed at the Martian surface attesting widespread aqueous alteration (e.g., Feldman et al., 2002; Squyres et al., 2004; Poulet et al., 2005b; Bibring et al., 2006; Ehlmann et al., 2013). Except the hydrated minerals situated in impact craters in the northern lowlands (Gendrin, 2005; Bibring et al., 2007; Loizeau et al., 2007; Milliken et al., 2008; Ehlmann et al., 2009; Osterloo et al., 2010; Bishop et al., 2012). Almost all phyllosilicates, the most abundant mineral species detected so far, are exposed on Noachian terrains and are thought to have mainly been formed at a time when liquid water was available on the surface during the Noachian/Early Hesperian epoch. Hydrothermal alteration, both volcanic and impact induced, seems to emerge as one of the most significant weathering processes leading to the formation of hydrous altered minerals on Mars (e.g., Carter et al., 2010; Fairén et al., 2010; Marzo et al., 2010; Ehlmann et al., 2011, 2013; Gross et al., 2012; Bishop et al., 2013). However, unaltered minerals occurring extensively at the Martian surface argue that aqueous alteration processes did not act pervasively in the ancient crust (Solomon et al., 2005). The largest quantities of hydrated mineral phases (sulfate minerals and clays) were identified in thick, layered deposits located at crater floors, connected plains and canyon systems (Interior Layered Deposits (ILDs)) (e.g., McCauley et al., 1972; McCauley, 1978; Lucchitta et al., 1994; Gendrin, 2005; Bishop et al., 2009; Roach et al., 2010; Ansan et al., 2011; Sowe et al., 2011). Proposed formation processes include subaerial, subaqueous, or subglacial volcanic processes (Peterson, 1981; Nedell et al., 1987; Chapman and Tanaka, 2001; Hynek et al., 2002), evaporation in a lake (McKay and Nedell, 1988), groundwater processes (Murchie et al., 2009), and the formation of spring deposits (Rossi et al., 2008). To date ongoing research along with the availability of higher resolution datasets definitely has led to a much better understanding of these features but likewise raised many questions such as for the water in any physical condition that seemed to have been present for a certain time period.

It is presently still being discussed if all this evidence for liquid water in fact indicates a generally warm and wet climate in Noachian times or if these warm periods occurred short-lived and infrequent (Solomon et al., 2005). Triggers for water release mechanisms could be large impacts resulting in the melting of subsurface ice and its evaporation to the atmosphere. Such events could and cause periods of precipitation that can last for decades, recharging groundwater aquifers (Solomon et al., 2005). Alternatively, volcanic eruptions, releasing significant amounts of magmatic water to the atmosphere can also explain a short-time, periodic, and local occurrence of fluvial activity (Phillips et al., 2001).

The following chapters will discuss a variety of water related research topics that help to refine the understanding of the climate history of Mars. The respective locations of example areas under investigation in the frame work of the Helmholtz Alliance are summarized in Fig. 1.

\section{Water-related environments on Mars}

\subsection{Fluvial environments}

Various fluvial landforms, partially associated with aqueous altered minerals, have been identified on the Martian surface (e.g., Magalhães, 1987; Bibring et al., 2006; Loizeau et al., 2007; Milliken et al., 2008; Ehlmann et al., 2009, 2013; Osterloo et al., 2010; Erkeling et al., 2012). The most prevalent fluvial landforms on Mars are valley networks, both dendritic and longitudinally patterned, attesting a recurring and widespread aqueous history. Studying the evolution of these fluvial systems is key to the interpretation of the timing and intensity of former fluvial water activity on Mars. Observations of fluvial landforms in the Libya Montes and in Newton Crater are of particular interest, because they allow constraining the water-related geologic record of 


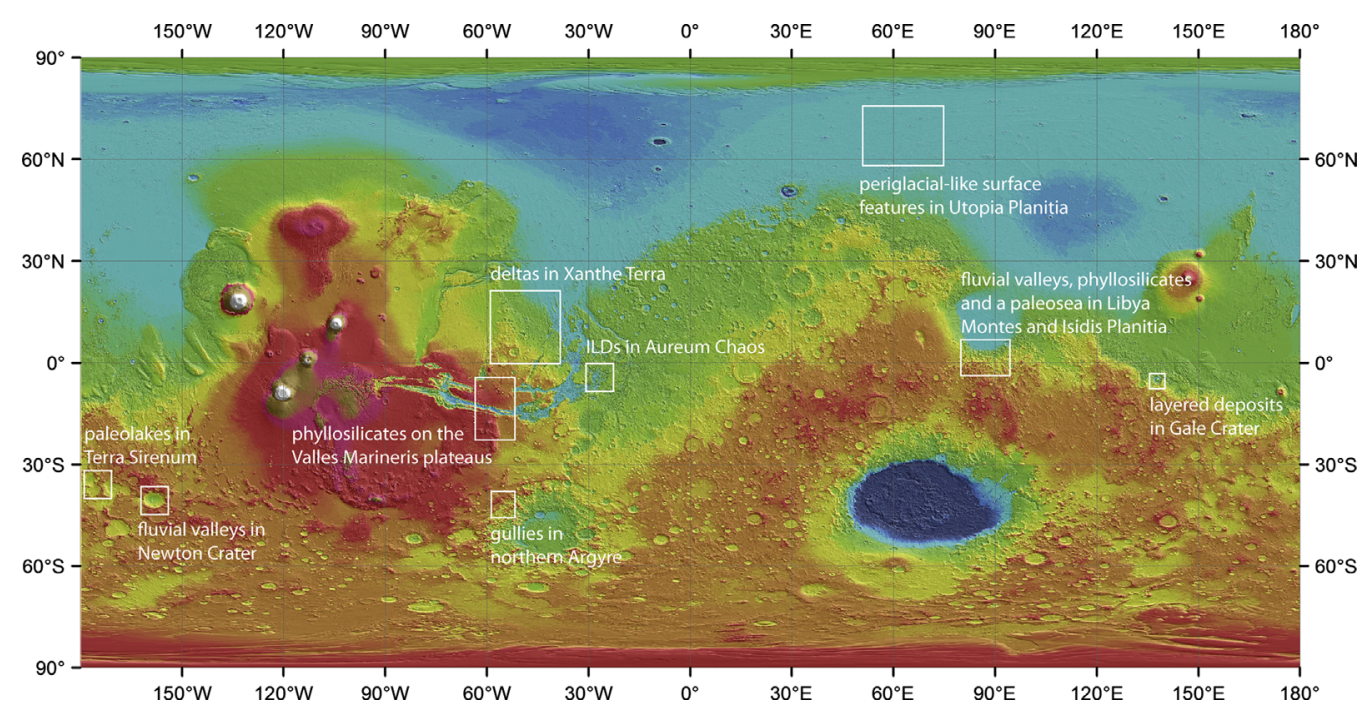

Fig. 1. Type localities of aqueous environments that have been studied in the frame work of the Helmholz Alliance. (Background: MOLA topography map.)

similar landforms in distinct geologic settings: a typical highland region located at an ancient rim of a giant impact basin at the equator (Libya Montes), and a large impact crater at the midlatitudes representing an example of spatially localized valley formation with significant influence by the local topography (Newton Crater).

The Noachian highlands of the Libya Montes, located along the southern margin of Isidis Planitia, are an example for extensive, longterm and repeated fluvial activity on early Mars that is inconsistent with the climate conditions on recent Mars. They reveal a large variety of hydrous landforms including abundant and dense valley networks, broad longitudinal valleys, paleolakes, deltas, alluvial fans and possible shorelines (Crumpler and Tanaka, 2003; Jaumann et al., 2005, 2010; Erkeling et al., 2010, 2012). The majority of the Libya Montes landforms shows Late Noachian to Early Hesperian model ages and were formed earlier than $\sim 3.5$ ( $\pm \sim 0.1$ ) Ga (Erkeling et al., 2010, 2012; Jaumann et al., 2010; Michael and Neukum, 2010), which is consistent with studies by Crumpler and Tanaka (2003). Particularly, the valley networks originating from mountain tops and crests are mostly dendritic and represent an initial period of valley erosion on early Mars, when fluvial activity was possibly controlled by precipitation-induced surface runoff. The morphologies of the dendritic valley networks, such as their repeated branching towards the upstream sections and their origin close to the summits of the Libya Montes mountains and on steep sloped crater walls support a formation by precipitation-driven surface water flow (e.g., Carr and Chuang, 1997; Mangold et al., 2004; Erkeling et al., 2010; Hynek et al., 2010; Jaumann et al., 2010). Dendritic patterns of valley networks can also point to downward percolation from superposed material such as glacial ice or snow (Lucchitta and Anderson, 1979; Lucchitta, 1982, 2001; Carr and Head, 2003; Gaidos and Marion, 2003). However, a formation due to glacial erosion is unlikely, because glacial landforms, as for example debris covered glaciers shown by Morgan and Head (2009), or morphologies that support subglacial flow such as eskers (e.g., Kargel and Strom, 1992), are absent within the Libya Montes. Morphometric indices, such as the valley density and the stream order reflect the original mode of hydrologic activity (Horton, 1945; Strahler, 1958; Gardiner and Gregory, 1982; Hou et al., 1997; Schumm, 1997) and revealed that the valley systems are mature and integrated. The ancient valley networks show maximum valley densities of $0.57 \mathrm{~km}^{-1}$ and the stream order ranges from 4 to 7 for drainage basins investigated throughout the Libya Montes (Erkeling et al., 2010). Age determination of fluvial geological units based on crater counts revealed that the formation of the eastern Libya Montes dendritic valleys occurred between $\sim 4.1$ and $\sim 3.8( \pm \sim 0.1) \mathrm{Ga}$ (Jaumann et al., 2010; Erkeling et al., 2010). Dendritic valley networks are absent in Hesperian-aged regions of Libya Montes (Erkeling et al., 2010) and in large areas of adjacent regions such as Amenthes Planum (Leverington, 2006; Erkeling et al., 2011) and Isidis Planitia (Erkeling et al., 2012; Ivanov et al., 2012). This suggests that valley formation due to rain or snowfall occurred mostly in the earliest times of the Martian history. Therefore, the termination of dendritic valley formation around $\sim 3.8$ ( $\pm \sim 0.1) \mathrm{Ga}$ is interpreted to be the result of a change of the erosive environment and climate conditions at the boundary from the Noachian to the Hesperian epoch at least in these regions.

The dissected landforms of Newton Crater, a $300 \mathrm{~km}$ sized impact basin located in Terra Sirenum on Mars $\left(40^{\circ} \mathrm{S} ; 157^{\circ} \mathrm{W}\right)$, attest an intense fluvial activity (Petau et al., 2012a, 2012b). Particularly the northern rim comprises both dendritic valley patterns and sapping induced structures. Dating of surfaces (Michael and Neukum, 2010) incised by the dendritic channels in this area yield an age of $\sim 3.56$ $(+0.04 /-0.05) \mathrm{Ga}$, whereas crater fill units at the basin floor show ages of $\sim 3.09(+0.11 /-0.18)$ Ga (Petau et al., 2012a). Dendritic patterns, which characterize the earliest fluvial phases, indicate surface runoff probably induced by precipitation of rain or snow in the Libya Montes region (Jaumann et al., 2005, 2010; Erkeling et al., 2010). Linear channels on late Hesperian surfaces imply that fluvial activity changed subsequently to groundwater sapping processes. The age of $\sim 3.09(+0.11 /-0.18)$ Ga marks the termination of dendritic activity in that region as this unit covers the mouths of the dendritic channels. Hence, the fluvial activity at Newton Basin covers a time span of at least a few $100 \mathrm{Ma}$. Newton's dendritic valley networks are slightly different in the temporal development of their fluvial activity. They have a maximum age of $\sim 3.56(+0.04 /-0.05)$ $\mathrm{Ga}$, which is the minimum age in the Libya Montes region; in other words: the dendritic activity in Newton started later in Martian history. Newton reveals well preserved topographic watersheds (Fig. 2) (Petau et al., 2012a, 2012b). They enclose three main catchment areas that can be divided into a western, central, and an eastern branch (Fig. 2), with stream orders of 4 and 5 (some dimensions lower than their counterpart in Libya Montes) and sizes between 1800 and $4200 \mathrm{~km}^{2}$. The valleys of the western and central catchments at Newton's crater rim started as dendritic patterns and enter the crater floor in one longitudinal channel, respectively. The eastern one drained into an enclosed basin and fed a standing body of water. Due to the good state of preservation of remnant channels Petau et al. (2012a) derived discharge rates $Q\left(\mathrm{~m}^{3} / \mathrm{s}\right)$ calculated by 


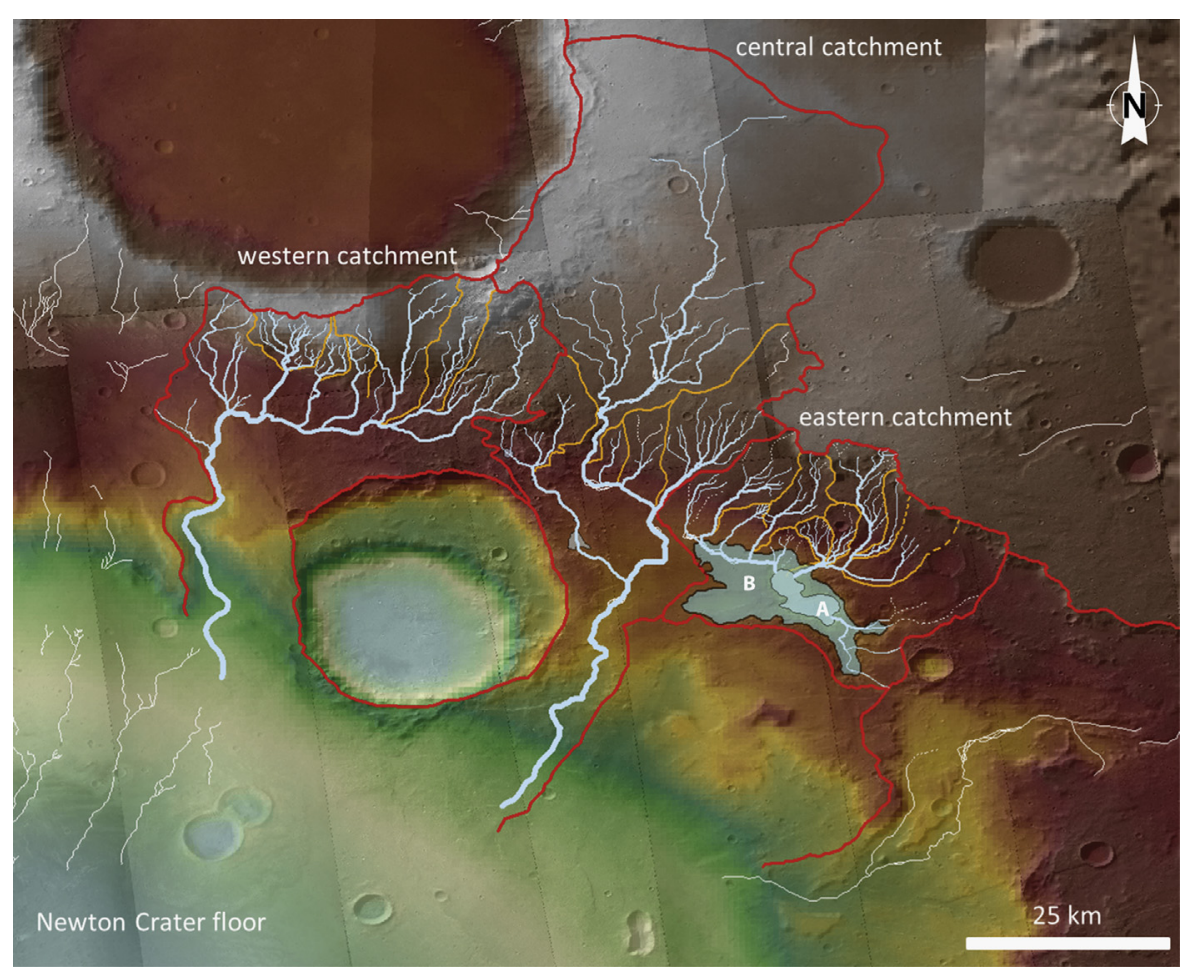

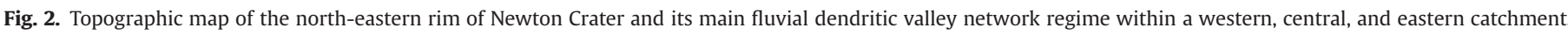

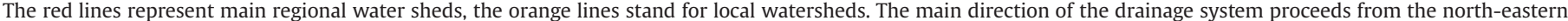

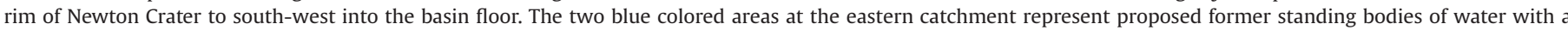

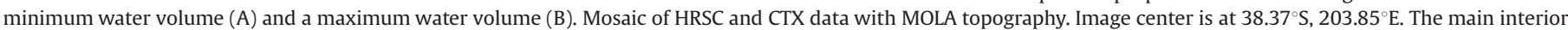
channels indicate discharges of $1000-1250 \mathrm{~m}^{3} / \mathrm{s}$. In connection with the catchment areas this results in runoff production rates of $2.9-5.6 \mathrm{~cm} / \mathrm{d}$.

using the empirical equation $Q=1.4 W^{1.22}$ (Irwin et al., 2005a), where $W$ is the average width $(\mathrm{m})$ of a channel. Based on this estimation the discharge of each fluvial system is equal to 1000 and $1250 \mathrm{~m}^{3} / \mathrm{s}$. Due to the complex drainage system of more than $1500 \mathrm{~km}$ length in relation to the small regional extent of the three catchments $\left(\sim 8500 \mathrm{~km}^{2}\right)$, relatively high amounts of surface runoff (up to some centimeters per day) were possibly responsible for the formation of the dendritic valleys. For comparison, Irwin et al. (2005a) calculated runoff production rates for different Martian valley networks yielding values between $0.1 \mathrm{~cm} / \mathrm{d}$ and $5.5 \mathrm{~cm} / \mathrm{d}$. Runoff rates in Newton Crater range around the uppermost dimension of rates calculated by Irwin et al. (2005a) and around the lowermost dimensions given by Hoke et al. (2011). In fact, the highest drainage densities are located at the highest elevations and steepest slopes on the entire northern inner rim with values between 0.15 and $0.3 \mathrm{~km}^{-1}$, overall consistent with that of Libya Montes derived by Erkeling et al. (2010). Nevertheless in comparison with the maximum drainage density in Libya Montes $\left(0.57 \mathrm{~km}^{-1}\right)$, Newton's maximum density is half the size of the Libya's one, which is consistent with the higher stream orders of the more extended Libya Montes region. Previous investigations led to drainage densities between $0.53 \mathrm{~km}^{-1}$ and $1.5 \mathrm{~km}^{-1}$ (Mangold et al., 2004; Ansan and Mangold, 2006).

Many authors suggest that Mars had a thicker and warmer atmosphere in its early days, which allowed a higher amount of water vapor than today (e.g., Craddock and Howard, 2002). Both Newton Basin and Libya Montes support this assumption. But in contrast to the extended Libya Montes region, Newton reveals an orographic effect. Due to its topography, local climate conditions and an atmospheric water cycle could have generated temporal and local recharging based on uplift of steam-rich air masses, followed by rainfall and surface runoff (e.g., Ansan and Mangold, 2006; Grant et al., 2011; Kite et al., 2011; Scanlon et al., 2013). Alternatively, a hydrological cycle fed by snow would comprise snow packages, accumulated at the crater rim over long timescales. In this case melt water could have drained into Newton Crater and formative a standing body of water feeding the atmosphere with vapor (Carr, 2001). Significant melting of snow packets requires a climate featuring long-term mean temperatures above the freezing point, as occurring during periods of high obliquity (e.g., Laskar et al., 2002, 2004). The geologic setting of valley networks in Newton Crater suggests precipitation with special consideration of orographic effects, surface runoff and valley formation, which are the results of appropriate local environmental and climate conditions.

In summary, the investigations of both valley networks close to the equator (Libya Montes) and in mid-latitudes (Newton Crater) point to commonalities. Both regions show the ancient development of dendritic and longitudinal valleys, generally similar drainage densities and stream orders, but with differences in their maximum values (higher ones in Libya Montes), which is an indication for more intensive erosion processes in several places, that is consistent with generally higher erosion events in the Noachian. The fluvial activity in the Libya Montes shows a change in erosion style from precipitation controlled dendritic dissection to more subsurface water release controlled sapping forming longitudinal valleys at about $3.8 \mathrm{Ga}$ and ceased at $\sim 3.5 \mathrm{Ga}$, while there was still some spatially isolated activity until the midAmazonian (Jaumann et al., 2010). The fluvial erosion in Newton Crater shows the same change from precipitation controlled dendritic dissection to sapping-like groundwater release. However, this happened later than in the Libya Montes. It is most likely that orographic effects present in Newton Crater contributed to the origin of spatially limited patterns of dendritic valley networks and are not attributed to global environmental conditions at the Noachian-Hesperian boundary. However, Newton Crater shows that fluvial processes operate on a local scale in the same way as 
they do on a more regional scale (Libya) with comparable drainage densities, stream orders and discharges at different times. One possible interpretation of this observation is that the change in erosion style - precipitation induced dendritic dissection to sapping caused headward erosion - is not only due to a global change of climate conditions, but also occurs when the local conditions change. Presumably, the amount of surface/subsurface water determines the fluvial erosion style. If the availability of surface water decreases by seepage and subsurface drainage, sapping starts to dominate until the amount of available groundwater drops below a certain threshold. While this can happen at different times and places it seems to be a fundamental geological process on Mars. Nevertheless, the extent of this process is time-dependent. The change in fluvial erosion style is global at the Noachian-Hesperian boundary and shrinks afterwards to smaller regions with specific orographic climate conditions.

\subsection{Lacustrine environments}

While geomorphological and mineralogical evidence suggests that liquid water was once present at and near the surface of Mars (e.g., Baker, 2001; Bibring et al., 2006), among all of the geomorphological water-related features, paleolakes are privileged targets for the search of traces of life on Mars because they indicate a sustained presence of liquid water. Knowledge on their temporal and spatial occurrence provides significant constraints on the surface water availability through time. Most paleolakes are distributed in the Noachian highlands of Mars and are thought to have mainly formed during the Noachian/Early Hesperian Epoch (Cabrol and Grin, 1999, 2001; Fassett and Head, 2008a; Grant et al., 2008; Ansan et al., 2011). Widespread and numerous exposures of phyllosilicate-bearing material and outcrops in the Martian southern highlands (e.g., Poulet et al., 2005a; Ehlmann et al., 2013) show globally distributed water in the Noachian period. The analysis of fluvial geomorphology holds the view that Noachian was the period when water was most abundant on the surface; however the duration and intensity of fluvial processes in the Noachian period is still unknown.

To constrain the chronology of hydrological processes occurring during the Late Noachian/Early Hesperian, Adeli et al. (2012, 2013) studied paleolakes in Terra Sirenum at about $35^{\circ} \mathrm{S}$ and $180^{\circ} \mathrm{E}$ (Fig. 3). This region in the southern cratered highlands is believed to have once contained a $\sim 1.1 \mathrm{M} \mathrm{km}^{2}$ lake, so called Eridania Lake that eventually drained through the large Ma'adim Vallis outflow channel (Irwin, 2004). As Eridania Lake dried out, it divided into a series of isolated and smaller lakes, including: Atlantis Chaos, Gorgonum Chaos, Ariadnes Colles and two unnamed basins. The floors of these basins are partly dominated by hills (knobs), which are composed of light-toned materials interpreted as $\mathrm{Fe} / \mathrm{Mg}$-rich phyllosilicates (Howard, 2004; Glotch et al., 2010; Annex and Howard, 2011; Davila et al., 2011; Ruesch et al., 2012; Wendt et al., 2012). Adeli et al. $(2012,2013)$ mainly focused on the $240 \mathrm{~km}$ diameter Atlantis Basin (centered at $34.28^{\circ} \mathrm{S}$ and $182.69^{\circ} \mathrm{E}$ ) that is the deepest basin among the others, and two unnamed basins located south and southwest of Atlantis Basin. The light-toned materials enriched in Fe/Mg-phyllosilicates (saponite/vermiculite) constituting the knobs, built the oldest unit that was deposited in these basins, likely in a lake (Adeli et al., 2012). The size distribution of knobs varies from larger knobs near the center of the basin to smaller ones at the basin rim, which is suitable with knob material once being continuous and thicker near the center, and being deposited in a standing body of water. Lack of shoreline evidence for the large Eridania Lake and, on the other hand, the clear evidence of the presence of smaller lakes in isolated basins, may reveal that Eridania Lake did not last over a long geological time. Instead, Eridania Lake may have been converted relatively quickly to smaller lakes, which may have existed for a longer time allowing the alteration of the sediments into clays. The knobby shape of these materials might be the result of aqueous and/or aeolian erosions after desiccation of the possible lake. The lighttoned materials also locally outcropped in the shallower peripheral parts of these basins, along the basin rims. They are often observed close to fluvial channels. Mineralogical studies reveal a sequence of Al-phyllosilicates (kaolinite) lying on top of $\mathrm{Fe} / \mathrm{Mg}$ rich phyllosilicates in these outcrops, which have likely been exposed by Late Hesperian or Early Amazonian aqueous activities. After the lake desiccation, the percolation of water (from precipitation or melted snow/ice) may have produced a widespread top-down weathering of the ground, producing such a sequence of phyllosilicate-rich materials. Such top-down weathering have been proposed to explain the formation of phyllosilicates in other regions of Mars (e.g., Gaudin et al., 2011; Le Deit et al., 2012; Carter et al., 2013). The current shape and the presence of two different phyllosilicate-rich formations in these basins suggest that multiple alteration, erosion and aqueous episodes occurred in Terra Sirenum.

Significant evidence for standing bodies of water on the surface of Mars was also found at the boundary between the Libya Montes and southern Isidis Planitia (Erkeling et al., 2012). Support for a lacustrine origin and standing bodies of water is likewise provided by multiple occurrences of closed- and open-basin paleolakes and delta deposits in the Libya Montes highlands (Cabrol and Grin, 1999, 2001; Crumpler and Tanaka, 2003; Erkeling et al., 2012). Observations of these deposits revealed layers rich in phyllosilicates that indicate transportation and alteration of minerals by liquid water, for example Al-phyllosilicates (montmorillonite) identified in the bottomset beds of a delta and Fe/Mg-phyllosilicates (smectites) identified in multiple lobes of an alluvial fan (Erkeling et al., 2012). In general, the phyllosilicates identified in the Libya Montes and elsewhere on Mars are of particular interest because they are candidate places to find possible organic materials.

In addition, the landforms associated with the Arabia contact have been interpreted as a putative global paleoshoreline that is possibly the result of a paleoocean (e.g., Parker et al., 1989, 1993). However, the majority of possible Martian coastlines, such as cliffs, benches and ridges, have been interpreted as wrinkle ridges, aeolian landforms, remnants of impact craters, scarps and lobate flow fronts volcanic in origin (e.g., Webb, 2004; Ghatan and Zimbelman, 2006). However, this is unlikely for the cliffs, terraces and platforms identified between the Libya Montes and southern Isidis Planitia. In particular, the cliff morphologies of the Arabia contact in southern Isidis are similar to those ridges and cliffs that have been interpreted by Ghatan and Zimbelman (2006) (see Figures 15e and 17b in Ghatan and Zimbelman (2006)) as reasonable candidates for coastal landforms. Based on the absence of volcanic sources a formation by lava deposition can be excluded (Erkeling et al., 2012). Detailed investigations of the landscapes in the vicinity of the Arabia contact in southern Isidis Planitia indicate that also tectonic, aeolian, and glacial processes cannot explain the geologic setting consistently and unlikely resulted in the formation of the cliffs (Erkeling et al., 2012). The cliffs and benches of the Arabia contact in Isidis Planitia are also comparable to analogous terrestrial oceanic coastal landforms (e.g., Bradley and Griggs, 1976; Adams and Wesnousky, 1988). Therefore, the Arabia contact in southern Isidis Planitia may be the result of longterm wave cut action and sea level variations of a sea-size standing body of water that possibly filled the Isidis Basin in the Hesperian (Erkeling et al., 2012). The Deuteronilus contact, the second global paleoshoreline, is also located at the boundary between the Libya Montes and the Isidis Basin. The morphologies of the contact, including its onlap geometry and the lack of cliffs, are significantly 

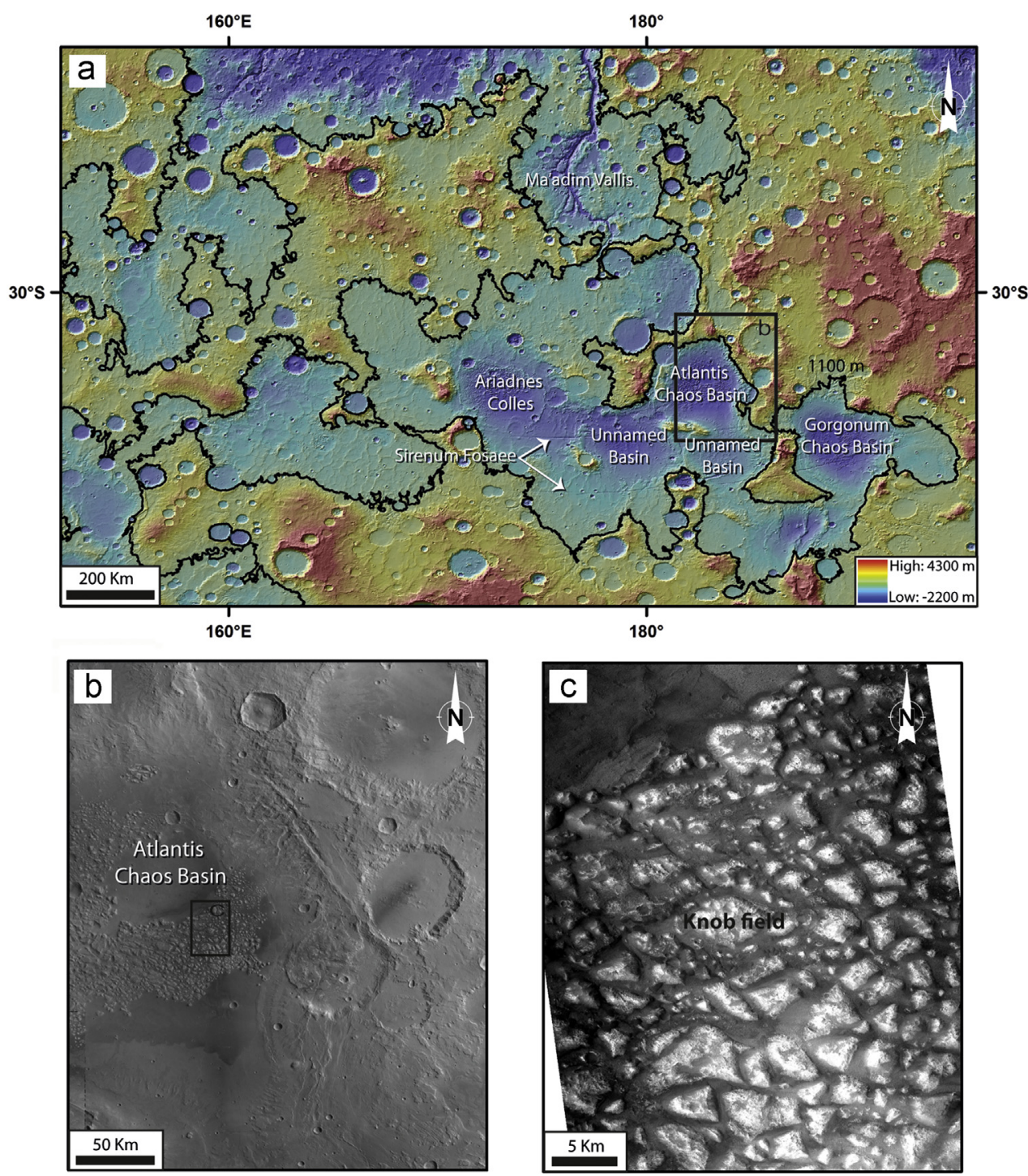

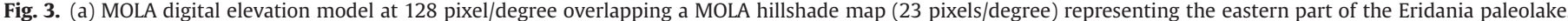

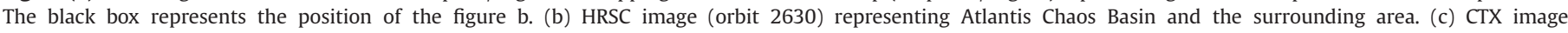
(P07_003702_1440_XN_36S176W) showing the knobs which covers partly the floor of this basin, and are composed of light-toned material.

different to the landforms identified at the Arabia shoreline and indicate the absence of long-term standing water and wave-cut erosion. The morphologic setting of the Deuteronilus contact supports more likely a late stage and short-lived Isidis sea (Erkeling et al., 2012), similar to the proposed primordial ocean that filled the northern lowlands of Mars (e.g., Parker et al., 1989, 1993; Kreslavsky and Head, 2002; Carr and Head, 2003).

Knowledge on the timing of fluvial and lacustrine processes is critical for the understanding of the aqueous surface evolution of Mars. Although numerous deltas and fan-like deposits on Mars point to the former existence of lakes, only few of them are obviously linked to dendritic valley networks (Pondrelli et al., 2005, 2008). Hence, it is not clear whether the deltas are records of the same epoch of fluvial activity as the valley networks. To constrain the chronology of delta formation, and indirectly lacustrine processes, Hauber et al. (2009) selected a population of deltas and fan-like deposits in Xanthe Terra. These deltas are not linked to dendritic valley networks, but to deeply incised valleys with few tributaries, uniform widths, and amphitheater-shaped headwalls (Hauber et al., 2009) (Fig. 4). The ages of the deltas as determined by crater counting techniques are consistently postNoachian in time and range from the Early Hesperian to the Late
Amazonian. Similar ages were obtained for a set of morphologically analogous deltas in the eastern hemisphere, which were studied for comparison. It appears that these results concerning deltas are not restricted to a specific region, but are globally representative (Hauber et al., 2013). Valleys with associated deltas were formed by short-lived aqueous processes, as indicated by morphologic observations, a lack of associated alteration minerals, and fluvial transport modeling (Kleinhans et al., 2010). Water was mobilized from the cryosphere and was not provided directly by widespread precipitation or by a regionally connected groundwater aquifer. Therefore, the formation of valleys and related deltas did not require sustained periods of global climatic conditions favoring widespread precipitation.

Lacustrine features on Mars cover different classes including desiccation lakes, shorelines and deltas. They are widespread over time and localities but seem, similar to the fluvial features, not require sustained long lasting wet periods to form.

\subsection{Alteration products}

On the other hand, the occurrence of rocks bearing alteration minerals (e.g., clays, sulfates, ferric oxides, carbonates) shows that 
aqueous processes have been involved in their formation. These aqueous processes must have happened on a sufficiently long-term basis to allow the aqueous minerals precipitation. Thus, altered rocks are sites of special interest to study the former habitability of Mars. To constrain the environmental and climatic conditions in which these alteration products formed, the morphology, the distribution, the stratigraphy, and the composition of alteration products in different settings in Valles Marineris, its surrounding plateaus, and in Gale crater have been studied (Le Deit et al., 2010, 2012; Sowe et al., 2012; Le Deit et al., 2013).

On the plateaus surrounding Valles Marineris Le Deit et al (2012) mapped an extensive Al- and Fe/Mg-phyllosilicate-rich formation covering at least $197,000 \mathrm{~km}^{2}$, for which they introduced the name "Plateau Phyllosilicates" (see Fig. 5a). Tens of meters in thickness, this light-toned formation crops out at various elevations on top of Noachian terrains, as flat exposures on

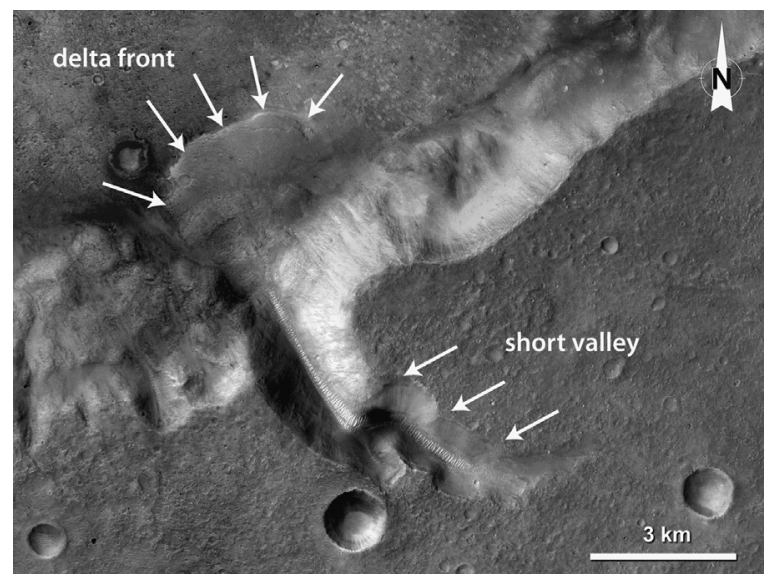

Fig. 4. Example of small delta in Xanthe Terra and around Chryse Planitia. The deltaic deposit was fed from a short and deep valley without tributaries (north of Aram Chaos at $14.09^{\circ} \mathrm{N}, 335.70^{\circ} \mathrm{E}$; detail of CTX image B17_016460_1943). plateaus and along scarps such as valley walls, chasma walls, pit walls and impact crater rims. The Fe/Mg-phyllosilicate-rich lower member of the formation is composed of $\mathrm{Fe} / \mathrm{Mg}$-smectites (nontronite, saponite) and vermiculite. The Al-phyllosilicate-rich upper member of the formation contains Al-smectites (montmorillonite, beidellite) and locally kaolinite and/or halloysite. From these observations and by analogy with terrestrial processes, Le Deit et al. (2012) suggested that the Plateau Phyllosilicates were mainly formed by pedogenesis related to the weathering of the Noachian bedrock by percolation of episodic meteoric water or melted snow through time. Mineral assemblages and stratigraphic relationships suggest that the Plateau Phyllosilicates developed in a neutral to alkaline environment during the Noachian Epoch (Le Deit et al., 2010, 2012; Sowe et al., 2012; Le Deit et al., 2013). Since iron smectites (e.g., nontronite) are only preserved in environments that are not too hot or too humid in volcanic soils on Earth (Chamley, 1989), the presence of nontronite in the Fe/Mg-member of the Plateau Phyllosilicates suggests that this member formed under a subarid climate, or even a possibly dryer climate. Kaolinite and/or halloysite may have formed in localized areas of more intense drainage at the surface under slightly acidic environments during the Noachian and Hesperian Epochs. Hence, this study suggested that the alteration of the Noachian crust was widespread in this region during the Noachian Epoch, and was still active during the Hesperian Epoch even with a smaller relative importance. This kind of Plateau Phyllosilicates has also been described in other regions of Mars including Mawrth Vallis (Loizeau et al., 2007; McKeown et al., 2009; Noe Dobrea and Swayze, 2010), Nili Fossae (Ehlmann et al., 2009; Gaudin et al., 2011), western Arabia Terra (Noe Dobrea and Swayze, 2010), northeast Noachis Terra (Wray et al., 2009), and in other sites scattered over the southern ancient highlands (Carter et al., 2013). Ehlmann et al. (2011) proposed that these kind of Plateau Phyllosilicates may have been formed by deep hydrothermal circulation instead of pedogenesis. However, the presence of Alphyllosilicates in many regions would be difficult to explain with
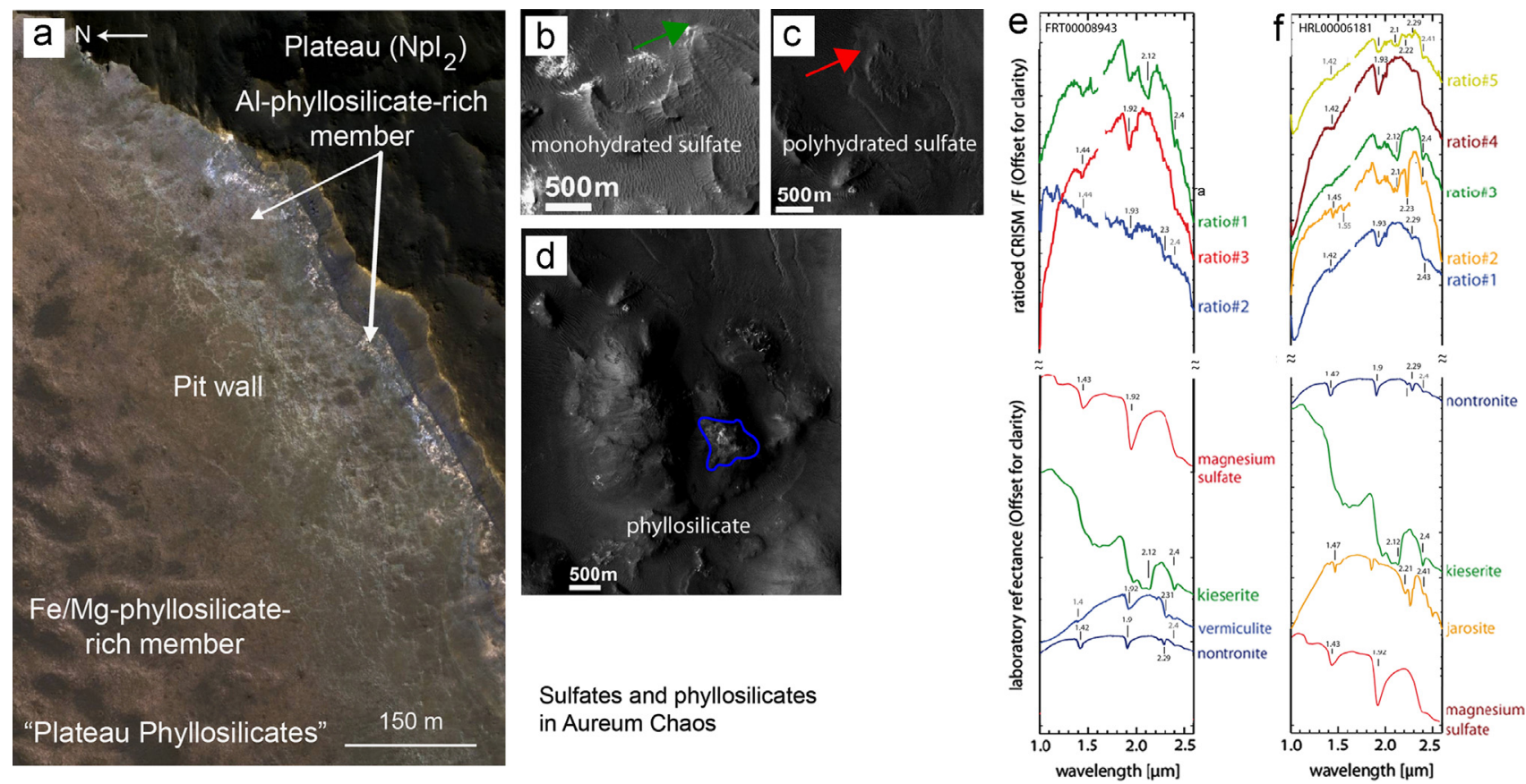

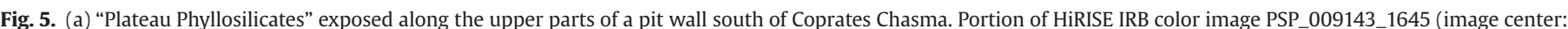

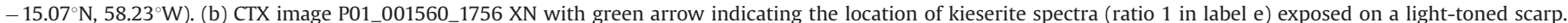

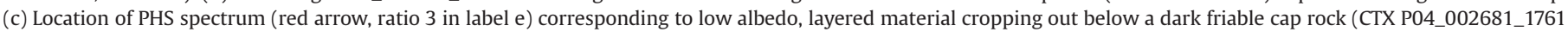

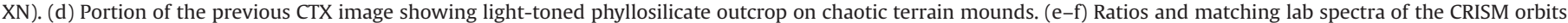
FRT00008943 and HRL6181. 
this formation process (Carter et al., 2013). This widespread distribution of Plateau Phyllosilicates gives evidence that alteration of the Noachian basement occurred on a wide scale in the Martian history.

To constrain the possible evolution of the environmental conditions in the region of Valles Marineris, Le Deit et al. (2010) studied sedimentary deposits, named "Layered Deposits" (LDs) herein, consisting of a $100 \mathrm{~m}$ thick series of alternating light and dark beds that cover the plateaus around Valles Marineris. They are stratigraphically above the Plateau Phyllosilicates and were deposited during the Hesperian and possibly later depending on the region. Because of their wide spatial coverage $\left(42,300 \mathrm{~km}^{2}\right.$ at least) and their high elevated plateau setting, Le Deit et al. (2010) suggested that LDs correspond to air fall dust and/or volcanic ash. The association of all LDs with valley systems and the occurrence of LDs within inverted channels indicate that at least portions of LDs are fluvial in origin (e.g., Weitz et al., 2008, 2010). Analyses of CRISM data showed that the LDs contain amorphous silica such as opal, and hydroxylated ferric sulfates in various proportions depending on the region (Milliken et al., 2008; Bishop et al., 2009; Le Deit et al., 2010). These mineral phases are consistent with aqueous alteration by sulphur-rich acidic solutions under oxidizing conditions of unaltered basaltic substrate (e.g., Tosca et al., 2004) or phyllosilicate-rich substrate, which may correspond to the Plateau Phyllosilicates. Experimental studies (Altheide et al., 2010) showed indeed that nontronite is fully degraded under acid leaching at $\mathrm{pH} \leq 4$, resulting in a mixture of hydrated amorphous silica and Al- and Fe-sulfates.

Kilometer-thick sequences of layered deposits named Interior Layered Deposits (ILDs) fill the Valles Marineris canyons and the eastern chaotic terrains (Fig. 6). Hydrated minerals were mapped in Aureum Chaos, a $295 \mathrm{~km}$ wide circular depression that is dominated by chaotic terrain and ILDs (Sowe et al., 2012). The latter are classified as Hesperian in age (Scott and Tanaka, 1986) and reveal morphological similarities to other layered deposits and the presence of polyhydrated sulfates and iron oxides (Glotch and Christensen, 2005; Glotch and Rogers, 2007; Noe Dobrea et al., 2008). Three stratigraphic units within local ILDs have been identified (Sowe et al., 2012). The lowest unit shows massive and layered, high-albedo monohydrated sulfate (MHS, best matching kieserite; 20-650 m thick) with intercalated hydroxylated ferric sulfates (HFS, best matching jarosite) and ferric oxides; overlying polyhydrated sulfate (PHS) is commonly layered (20-40 m thick), smooth to heavily fractured, of lower albedo and partially contains ferric oxides; spectrally neutral, distinctly layered, and bumpy cap rock (40-300 $\mathrm{m}$ thick) forms the top. The deposits show

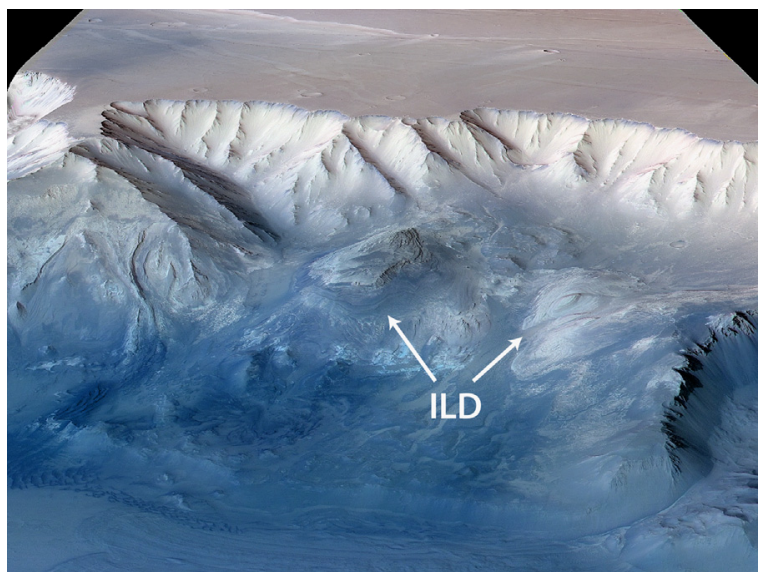

Fig. 6. Interior layered deposits (ILD) located on the northern wall of Coprates Chasma. The deposits (arrows) contain sulfate-bearing material (Fueten et al., 2010) and are typical of other ILD within the trough system of Valles Marineris. similarities in composition and morphology to those in chaos regions and also in chasmata of Valles Marineris, e.g. Aram Chaos (PHS, MHS; texture of ILD and cap rock), Juventae Chasma (HFS) and Ophir Chasma (kieserite, PHS) (Bishop et al., 2009; Lichtenberg et al., 2010; Wendt et al., 2011). The phyllosilicate nontronite was found in the chaotic terrain as light toned fractured exposure and within dark, smooth, and indurated mantling but spatially close to sulfate-bearing ILDs. Sowe et al. (2012) could not define facies or relative timing of the layered deposit and sulfate formation and considered two models: (1) Formation of one sulfate type (either kieserite or PHS) e.g. by evaporation in a lake (or even freeze-drying? (Möhlmann and Thomsen, 2011)) and its alteration later on. Ice-weathering has been assumed for these kind of deposits by (Niles and Michalski, 2009). The occurrence of PHS along mantling edges and on flat surfaces of kieserite without textural differences makes PHS a potential alteration product of kieserite, e.g. due to surface exposure. (2) Post-ILD sulfate formation by groundwater intruding into previously formed, sulfate-free ILDs would be another formation hypothesis (AndrewsHanna et al., 2007) that was suggested for other localities with sulfate-bearing ILDs (Wendt et al., 2011). Surface age of the ILD is constrained by stratigraphic relationships to be within chaotic terrain (Late Hesperian) and mantling deposits (Mid to Late Amazonian). Nontronite observed in chaotic terrains could have been formed locally and is assumed either after the Noachian or instead during the Noachian following the Phyllosian era proposed by Bibring et al (2006). Apart from that, a close spatial association of sulfates and phyllosilicates could be considered as temporally close as well (Baldridge et al., 2009). If ascending groundwater produced the observed mineralogy, nontronite would represent the low facies and sulfates the shallow facies. However, the preservation of nontronite, HFS, and MHS indicates a relatively dry environment with intermittent aqueous activity since their emplacement within Aureum Chaos deposits, which is in agreement with the studies lead on the plateaus surrounding Valles Marineris (Le Deit et al., 2012).

The sedimentary infill of Gale Crater has been studied using recent orbital data (Le Deit et al., 2013). The occurrence of channels carved along the crater rim and along its $5 \mathrm{~km}$ thick central mound of layered deposits, so called Aeolis Mons, (Malin and Edgett, 2000b), the detection of sulfates and clays from orbit (Milliken et al., 2010), and the presence of possible terraces (Cabrol et al., 1999) are strong hints for repeated and possibly diverse aqueous activity in Gale (e.g., Thomson et al., 2011). The recent Mars Science Laboratory (MSL) (Grotzinger et al., 2012) in situ investigations of conglomerates in a hypothetic alluvial fan and of light-toned veins enriched in hydrated calcium sulfate (Mangold et al., 2013; Williams et al., 2013) on the crater floor confirm that liquid water once occurred in Gale Crater. From the geological mapping of Gale and geometric measurements of the layered sediment, LeDeit et al. (2013) interpret the sediment of Aeolis Mons to be primarily airfall material such as dust, volcanic ash, and fine-grained impact products deposited by settling from the atmosphere and cemented in the crater center (Fig. 7). Windblown sands are also likely contained in the sediment. The upper unit of the mound rather primarily corresponds to aeolian sands. The occurrence of stepped fan-shaped deposits and the morphology of the crater floor material deposited around Aeolis Mons and on the crater wall suggest that they correspond to alluvial and colluvial deposits formed during the Hesperian. A suite of several features including patterned ground and possible rock glaciers are suggestive of periglacial processes with a permafrost environment after the first hundreds of thousands of years following its formation, dated to $\sim 3.61(+0.04 /-0.06)$ Ga (LeDeit et al., 2013). Possible coastal landforms including a fan delta, terraces, and a shoreline suggest the presence of a shallow paleolake after the formation of the lowermost layers of Aeolis Mons. Episodic melting of snow in the crater may have caused the formation of 


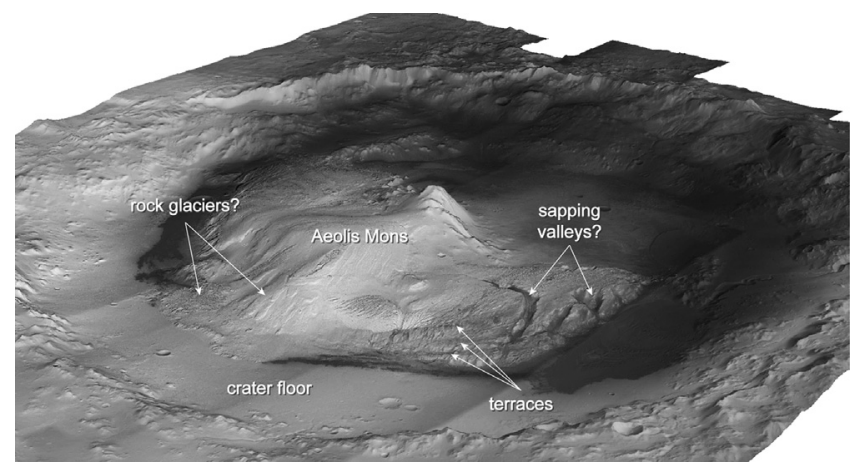

Fig. 7. Oblique view towards southeast of Gale crater (CTX mosaic overlain on a HRSC DEM, vertical exaggeration: $\times 2$ ). The crater measures $150 \mathrm{~km}$ in diameter.

sulfates and clays in Aeolis Mons. Overall, those studies of alteration products suggest that the Martian climate was relatively dry with intermittent aqueous activity throughout the planet history, allowing the alteration of the surface at a large scale which is consistent with the results of fluvial and lacustrine observations.

\subsection{Hydrothermal environments}

The surface of Mars shows ample evidence of volcanic deposits and the existence of an extensive cryosphere/groundwater system (e.g., Tanaka et al., 1992; Clifford, 1993; Greeley et al., 2005). Hence, it is reasonable to assume that, among others, interactions between an internal heat source and the cryosphere/groundwater enabled the formation of a hydrothermal system on Mars. Diagnostic for such hydrothermal activity on Earth, are for example hydrated silicate minerals that are typically formed by an extended exposure of silicates to abundant water (Tornabene et al., 2013). On Mars, the identification of hydrothermal minerals mostly in the ancient Noachian period has frequently been used as evidence for a once warmer and wetter Mars, despite that fact that climate models have difficulties in reproducing stable water during this epoch (e.g., Kasting, 1991; Colaprete and Toon, 2003). Provided Mars was cooler and drier on its surface with only sporadic and transient water-related events (e.g., McEwen et al., 2007; Christensen et al., 2008), one has to consider a formation of hydrated minerals in special environments, including the subsurface and impact craters (e.g., Ehlmann et al., 2011; Osinski et al., 2013; Tornabene et al., 2013). Ehlmann et al. (2011) argued that most clay minerals, specifically the $\mathrm{Fe} / \mathrm{Mg}$ clay minerals were formed in closed systems at temperatures varying from ambient to $<400{ }^{\circ} \mathrm{C}$ and later exhumed/excavated by impact craters. In such closed systems, water is isolated from the atmosphere and approaches chemical equilibrium with precursor rocks. This isolation also has influence on the temperatures, pressures, redox conditions, $\mathrm{pH}$, and ion activities, and water-to-rock ratios. In such an environment, lateral transport is limited, which results in an isochemical alteration of rocks (Ehlmann et al., 2011). Open systems, i.e., systems that have contact with the atmosphere, have higher water-to-rock ratios, which results in leaching and changes in the bulk elemental composition. In addition, $\mathrm{pH}$-values are more acidic, which causes magnesium, calcium, and sometimes silica to become more mobile, while aluminum, iron(III), and titanium remain immobile. Consequently, as weathering of mafic rocks proceeds, residual rocks become more aluminum rich. Leaching of mafic rocks results, for example, in Al-clays (kaolinite, montmorillionite) and iron oxide assemblages. Additionally, more acidic $\mathrm{pH}$-values hinder the formation of $\mathrm{Fe} / \mathrm{Mg}$ smectites (Ehlmann et al., 2011). Bridges and Schwenzer (2012) investigated Martian nakhlite meteorites to thermochemically model the composition, temperature and redox conditions of the water that formed the observed hydrous alteration. They showed that the nakhlite parent rocks on Mars encountered a $\mathrm{CO}_{2}$-rich hydrothermal fluid at $150 \leq T \leq 200{ }^{\circ} \mathrm{C}, \mathrm{pH} 6-8$ with a water-to-rock ratio $(\mathrm{W} / \mathrm{R}) \leq 300$. Under these conditions, Fe-rich carbonates were precipitated within brittle fractures. As the fluid cooled to $50{ }^{\circ} \mathrm{C}$, at pH 9 and a water-to-rock ratio of 6, Fe-rich phyllosilicate precipitated, followed in turn by rapid precipitation of an amorphous gel. It was enriched in the most soluble species (e.g., $\mathrm{K}, \mathrm{Na}$ ), of alkaline $\mathrm{pH}$, and similar to terrestrial, i.e., not seawater-influenced, dilute brines in basaltic terrains on Earth (Bridges and Schwenzer, 2012). Bridges and Schwenzer (2012) concluded that environments associated with this type of fluid were habitable, unlike those associated with acid-sulphate fluids. Considering the timing of the nakhlite alteration, they argued for an impact-generated hydrothermal alteration of the nakhlites at the margins of an impact crater. While only a small number of extensive Noachian terrains (near Argyre, Terra Sirenum, Claritas Fossae, Nili Fossae) show evidence for hydrothermal activity, most deposits are associated with impact craters (e.g., Wyatt et al., 2001; Mustard et al., 2008, 2009; Buczkowski et al., 2010; Ehlmann et al., 2011; Bishop et al., 2013). Not only are impact craters important for the exhumation/excavation of hydrothermal minerals, but also for the formation of their own hydrothermal systems that might have been potential habitats for early life (Osinski et al., 2013). Schwenzer et al. (2012) have modeled the consequences of impacts into a 2-6 km-thick cryosphere and concluded that even small impacts (5-20 km diameter) will physically and/or thermally disturb the cryosphere enough to create liquid water through the melting of subsurface ice in an otherwise dry and frozen environment. Interaction of liquid water with the substrate results in alteration phases, including hydrous silicates (e.g., nontronite, chlorite, serpentine) (Schwenzer et al., 2012). Osinski et al. (2013) proposed that there are six main locations associated with craters where hydrothermal systems are particularly likely to form. These locations include (1) crater-fill impact melt rocks and melt-bearing breccias, (2) interior of central uplifts, (3) outer margin of central uplifts, (4) impact ejecta deposits, (5) crater rim regions, and (6) post-impact crater lake sediments. From Earth, several types of impact crater-related hydrothermal minerals are known, including (1) hydrothermally altered target rock assemblages, (2) primary hydrothermal minerals precipitated from solutions, and (3) secondary assemblages formed by the alteration of primary hydrothermal minerals (Osinski et al., 2013). Products of post-impact hydrothermal activity at various terrestrial impact craters include hydrated silicate phases (e.g., quartz, saponite, montmorillonite, celadonite, kaolinite, halloysite, epidote, amphibole-group minerals, chlorite-group minerals, micas, zeolites). In addition, carbonates (calcite, dolomite) often form in terrestrial hydrothermal systems, as well as sulfides (e.g., marcasite, pyrite, bornite, chalcopyrite, spalerite, galena), native gold, platinum-group elements, oxides (e.g., magnetite, ilmenite), sulfates (e.g., gypsum), and halides (e.g., fluorite, halite) (Osinski et al., 2013). At least some of those minerals have also been spectrally detected on Mars, including $\mathrm{Fe} / \mathrm{Mg}$-rich smectites, Al-rich smectites, chlorite, phrenite, kaolinite, halloysite, silica glass, illite, and muscovite, sulfates, carbonates, serpentine, opaline silica, gypsum, jarosite, haematite, goethite, perchlorates, (e.g., Ehlmann et al., 2011; Tornabene et al., 2013). Bishop et al. (2013) identified surface outcrops and deposit of Fe/Mg-rich phyllosilicates and $\mathrm{Al}$-smectites in the central Libya Montes valley region. These aqueous minerals are located in the mouth region of a fluvial valley, featuring exposures of the deep bedrock and in the central peak of a $47 \mathrm{~km}$ diameter impact crater. Those units are either the result of hydrothermal alteration processes as a consequence of the Isidis Basin formation or of chemical alteration through pervasive fluvial activity (Bishop et al., 2013). 


\subsection{Permafrost environments}

According to the definition of permafrost (Everdingen, 2005), Mars may be considered a permafrost planet. It exhibits a wide variety of periglacial-like landforms that, based on stratigraphic relations and impact crater densities, appear to be very young. While these individual landforms are widely distributed on Mars, they form spatially associated assemblages (landscapes) primarily in mid-latitude regions. On Earth, periglacial landforms indicate specific cold-climate conditions, commonly involving freeze-thaw cycles, and they are typically, but not necessarily, linked to permafrost dynamics. A main question related to the recent climate of Mars concerns the existence of liquid water: Is it possible to explain the observed landforms by dry processes, only involving the condensation and sublimation of $\mathrm{H}_{2} \mathrm{O}$, or is the action of liquid water, in whatever amounts, required to form them? To contribute to possible answers to this question, Ulrich et al. (2010) and Hauber et al. (2011a) analyzed representative examples of such Martian landforms and performed analogue studies on terrestrial periglacial landscapes, comparing them to mid-latitude landforms on Mars that were hypothesized to be records of recent ice ages on Mars (Head et al., 2003a).

The mid- and high-latitudes of both hemispheres on Mars are covered by a smooth mantle deposit that is suggested to originate from airfall deposition of dust cemented by ice precipitated from the atmosphere (Mustard et al., 2001). Deposition and desiccation of this proposed dust-ice mantle is suggested to be caused by spinorbit variations (Laskar et al., 2002, 2004) in the recent past (Head et al., 2003a). These latitudinal bands on Mars are also characterized by a variety of landforms such as i.e., polygonal patterned terrain (e. g., Mangold, 2005; Levy et al., 2009), viscous flow features (e.g., Milliken et al., 2003), gullies (e.g., Malin and Edgett, 2000a; Balme et al., 2006; Kneissl et al., 2010), solifluction lobes (e.g., Gallagher et al., 2011; Johnsson et al., 2012) and scalloped terrain (Morgenstern et al., 2007; Lefort et al., 2010; Zanetti et al., 2010; Séjourné et al., 2011). Morphologically, these landforms resemble cold-climate features on Earth formed by freeze-thaw or thaw processes of $\mathrm{H}_{2} \mathrm{O}$-ice. Crater size-frequency distributions on homogenous dust-ice mantle deposits (Raack et al., 2012; Willmes et al., 2012) indicate that the last major deposition phases of the dust-ice mantle occurred within the last several million years. Degradational features within thick dust-ice mantle deposits (scalloped terrain) on Mars resemble terrestrial thermokarst landforms (Morgenstern et al., 2007). Studies on scalloped terrain (Ulrich et al., 2010) indicate that the last major deposition and degradation phases of the dust-ice mantle occurred within the last several million years. Morphologic analyses of the scalloped terrain showed that its formation can be explained by sublimation of a water-ice rich substrate, which was possibly supported by thaw processes causing mass wasting (Ulrich et al., 2010).

Apart from recently detected recurrent slope lineae (McEwen et al., 2011), gullies are probably the best evidence for transient liquid water activity on Mars in the recent past (e.g., Malin and Edgett, 2000a; Costard et al., 2002; Dickson et al., 2007). Age estimations of gullies based on crater size-frequency distributions indicate that they were active within the last few million years (Reiss et al., 2004; Schon et al., 2009). Many gullies on Mars are incised into dust-ice mantle deposits indicating that they evolved from thawing of $\mathrm{H}_{2} \mathrm{O}$-ice stored in the dust-ice mantle in the recent past (e.g., Christensen, 2003; Bleamaster and Crown, 2005; Reiss et al., 2009; Raack et al., 2012). Gullies eroding into the bedrock and not associated with the dust-ice mantle are possibly formed by snowmelt (Dickson et al., 2007; Head et al., 2008). Observed present-day gully activity on Mars is limited to the formation of small-scale channels or morphologic changes within larger gullies and is either caused by transient melting of small amounts of $\mathrm{H}_{2} \mathrm{O}$-ice (Reiss et al., 2010) or $\mathrm{CO}_{2}$-sublimation processes (Diniega et al., 2011; Dundas et al., 2012).

Various terrestrial permafrost environments and their characteristic landforms have been suggested as analogues of very recent Martian surface features that may be related to ice and perhaps some amount of liquid water. For example, pingos and ice wedge polygons in northern Canada have been proposed as analogues for fractured mounds and polygonally fractured ground in Utopia Planitia, respectively (Soare et al., 2005; Haltigin et al., 2010). On the extremes of cold and dry landscapes on Earth, the McMurdo Dry Valleys in Antarctica were long recognized as useful analogues for Mars (Anderson et al., 1972), and recent work has focused on detailed descriptions of their microclimates and related geomorphic processes (Marchant and Head, 2007). Of particular interest are sublimation polygons in the Dry Valleys (Marchant et al., 2002), because their formation does not involve freeze-thaw cycles. A similar process may occur on present-day Mars and form the ubiquitous polygons in the northern high latitudes on Mars (Levy et al., 2009). This example also illustrates the caveats of deducing processes from comparisons of morphologically similar (analogous) landforms, since landforms (e.g., polygons) at different sites may look almost identical, yet may have formed by different processes in different environments. Field campaigns were conducted at several sites in Siberia and Svalbard that display various glacial and periglacial landforms in continuous permafrost terrain (Ulrich et al., 2010; Hauber et al., 2011a). Examples of such landforms are rock glaciers (Hauber et al., 2008; Rossi et al., 2011; Van Gasselt et al., 2011) and patterned ground (Ulrich et al., 2011). The field work confirmed that remote sensing-based interpretations of some landforms (e.g., thermal contraction cracks), relating them to specific processes (e.g., freeze/thaw cycles), are complicated by the ambiguity of morphologic characteristics (equifinality) (Ulrich et al., 2011). Although this analogue sites were situated in relatively "wet" periglacial environments, the results suggest that many periglacial features on Mars may be explained by "dry" permafrost processes without the need to invoke liquid water (Hauber et al., 2011b), although several scenarios, which may not be mutually exclusive, could account for the observations. Nevertheless, it appears that at least limited amounts of liquid water are required to fully explain the morphology of gullies and debris flows in periglacial environments (Hauber et al., 2011b; Reiss et al., 2011; Johnsson et al., in press) and the existence of slope-related flow features interpreted as solifluction lobes (Jacobshagen et al., 2000; Johnsson et al., 2012). This notion is consistent with thermal modeling of a slope location in Utopia Planitia, where specific spin-orbit conditions have enabled thawing in the recent past, but not within the last few million years (Ulrich et al., 2012). These results are consistent with Levy et al., 2011, those who conclude that sublimation, not melting, is the main physical process of ice loss on Mars today, but that episodic melting in specific morphologic niches with favorable microclimates may occur and provides liquid water for gully formation.

\section{Implication for the evolution of water on Mars}

The surface of Mars exhibits numerous geomorphological landforms that are the result of fluvial and glacial processes. These features occur in all regions on Mars and were possibly formed throughout the entire geologic history of Mars, although with decreasing intensity over time. These features comprise erosional landforms such as dendritic and longitudinal valley networks, large outflow channels, small-scale gullies, lacustrine environments including paleolakes and deltas, weathering environments with layered chemical alteration products, and permafrost environments and their surface exposures. From a habitability point of view it is 
necessary to constrain the amounts of water and the time of its availability required to form certain fluvial and glacial features in order to constrain the time span available for organic evolution. It is obvious that the restricted accessibility to a number of factors such as small-scale features like river channel terraces, subsurface access of layered deposits, measurements of pore volumes, infiltration rates, and cryosphere thickness will complicate such quantitative analyses. Therefore, only rough estimates of water availability and the duration of fluvial and glacial processes can be achieved (e.g., Kreslavsky and Head, 2002; Harrison and Grimm, 2005; Irwin et al., 2005b; Jaumann et al., 2005, 2010; Schon et al., 2009, 2012; Fassett and Head, 2011; Carr, 2012; Erkeling et al., 2012). Nevertheless, the typical fluvial and glacial locations studied in context with the Helmholtz Alliance 'Planetary Evolution and Life' project, as discussed above, allow to roughly constrain the evolution of water on Mars.

Dendritic valley networks mostly occur in topographic elevated mountainous regions, probably above the level of groundwater release. The dendritic pattern of most of the valleys is poorly developed with low branching index and relatively large bifurcation angles indicating incomplete erosion. However, the valley patterns, the topographic position and the erosional style suggest surface runoff due to rainfall or melting of accumulated snow. For example, the ages of the Libya Montes dendritic valleys date to the Noachian with a termination of dendritic valley formation around 3.8 Ga (Erkeling et al., 2010, 2012). This can be interpreted as evidence for a change of the erosive environment and climate conditions at the boundary from the Noachian to the Hesperian epoch in this extended region. The discharges in the Libya Montes region range from $15,000 \mathrm{~m}^{3} / \mathrm{s}$ to $430,000 \mathrm{~m}^{3} / \mathrm{s}$ with an increase of up to one order of magnitude from precipitation to volcanic triggered groundwater release, and yield transported sediment volumes of up to $250 \mathrm{t} / \mathrm{s}$ (Irwin et al., 2005a; Jaumann et al., 2005, 2010; Hoke et al., 2011). These values are consistent with those at other regions on Mars (Irwin et al., 2005a; Jaumann et al., 2005, 2010; Hoke et al., 2011). The estimated discharge rates indicate the formation of the observed valleys on Mars within relatively short periods with episodic and multi-genetic erosion events over most of the Martian history. Studies show a clear change in the style of water release during the early Hesperian (from precipitation to ground-ice/water release due to induced volcanic heat) and surface runoff lasted until the mid-Amazonian (Irwin et al., 2005a; Jaumann et al., 2005, 2010; Hoke et al., 2011). Dissected landforms with dendritic patterns on the wall of Newton Crater also indicate fluvial activity due to surface runoff (Petau et al., 2012a, 2012b). Runoff production rates for the Newton valley system amount to about $5 \mathrm{~cm} / \mathrm{d}$ (Petau et al., 2012b), which is in the medium range of estimated Martian runoff production rates (Irwin et al., 2005a; Jaumann et al., 2005, 2010; Hoke et al., 2011). However, the concentration of these fluvial landforms at a relatively small, orographically controlled area as in the Newton Crater suggests specific locally defined climate conditions. The fluvial activity within Newton Crater presumably appeared episodically from the Noachian to the Hesperian. In summary, dendritic valley networks show evidence for precipitation in the Noachian but their spatial distribution, estimated discharge, and runoff production rates suggest limited erosion and rather episodically than continuous fluvial activity (e.g., Irwin et al., 2005b; Jaumann et al., 2005, 2010).

Other time constraints for aqueous periods are deltas. A population of deltas and fan-like deposits in Xanthe Terra imply that some valleys with associated deltas were formed by shortlived aqueous processes (Hauber et al., 2009), as indicated by fluvial transport modeling (Kleinhans et al., 2010). The formation of valleys and related deltas did not require sustained periods of global climatic conditions favoring widespread precipitation. Surface runoff and valley formation require slopes and terminate at base levels. Consequently most paleolakes on Mars are distributed in the Noachian highlands and have mainly formed during the Noachian/Early Hesperian Epoch (Fassett and Head, 2008a; Grant et al., 2008; Ansan et al., 2011). The lakes in Terra Sirenum, that formed by the drying of Eridiana lake (Adeli et al., 2012, 2013), are related to the large Ma'adim Vallis outflow channel (Irwin, 2004). The desiccation of the giant lake, resulting in the percolation of water, may have produced a widespread top-down weathering of the ground, producing a sequence of phyllosilicate-rich materials (Le Deit et al., 2012). Evidence for standing bodies of water on the surface of Mars is also found at the boundary between the Libya Montes and southern Isidis Planitia (Erkeling et al., 2012) and by multiple occurrences of closed- and open-basin paleolakes and delta deposits in the central Libya Montes highlands (Cabrol and Grin, 1999, 2001; Crumpler and Tanaka, 2003; Erkeling et al., 2010, 2012). Surface outcrops and deposit of Fe/Mg-rich phyllosilicates and Al-smectites are also found in the central Libya Montes valley region (Bishop et al., 2013). Those units are either the result of hydrothermal alteration processes as a consequence of the Isidis Basin formation or of chemical alteration through pervasive fluvial activity (Bishop et al., 2013).

Investigations of phyllosilicate formation processes in Valles Marineris, chaotic terrains and Gale Crater suggest that the clays developed in a neutral to alkaline environments during the Noachian Epoch. Some members formed under a subarid climate, others indicate a more intense drainage at the surface under slightly acidic conditions (Le Deit et al., 2012). The local phyllosilicate preservation points to a relatively dry environment with intermittent aqueous activity (Sowe et al., 2012).

Mars exhibits a wide variety of periglacial-like landforms that appear to be very young. Although many periglacial features on Mars may be explained by "dry" processes without the need to invoke liquid water (Hauber et al., 2011b), it appears that at least limited amounts of liquid water are required to fully explain the morphology of gullies in periglacial (Reiss et al., 2010).

All the observed erosional and depositional landforms that involve water or ice in their formation indicate relatively short processing times and more likely episodic than perseverative events.

\section{Summary and conclusions}

Liquid water is the most basic known prerequisite for life. Although other factors such as energy and nutrients are also necessary, any geological approach to habitability must start with the identification of zones where liquid water is or was active. There is consensus among most researchers that the surface of Mars displays many morphological features indicative of liquid water (e. g., MarsChannelWorkingGroup, 1983; Hynek and Phillips, 2001; Fassett and Head, 2005; Harrison and Grimm, 2005; Ansan and Mangold, 2006; Irwin et al., 2008; Barnhart et al., 2009; Bouley et al., 2009; Mangold et al., 2012). The occurrence of hydrated minerals suggests a wide range of surface alterations under the influence of water (e.g., Bibring et al., 2007; Bishop et al., 2008, 2012, 2013; Le Deit et al., 2010; Story et al., 2010; Erkeling et al., 2012; Gross et al., 2012; Sowe et al., 2012) providing nutrients and chemical energy.

Based on these observations, Mars can be considered habitable with respect to water, at least partly, in space and time. Research in the HGF Alliance has expanded the known database of aqueous environments (Fig. 8). This encompasses both the early history of Mars ( 4-3 billion years ago: Erkeling et al. (2010,2012), Jaumann et al. (2010), Petau et al. (2012a), Bishop et al. (2013), Warner et al. (2013)) and the very recent past (the last few years: Reiss et al. (2010), Ulrich et al. (2010), Raack et al. (2012)). Studies in context with Helmholtz Alliance 'Planetary Evolution and Life', as discussed above, have also constrained the duration of geological 


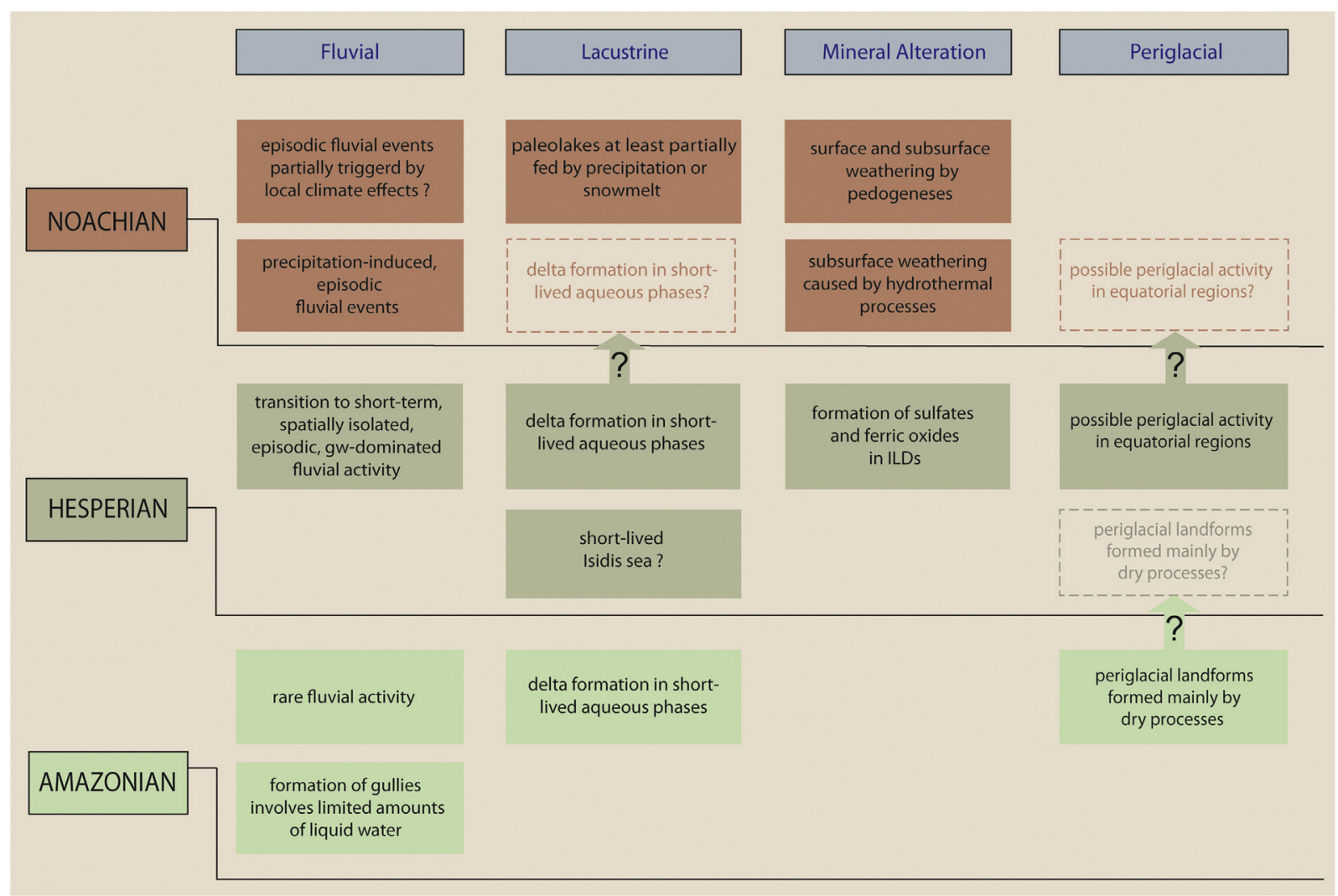

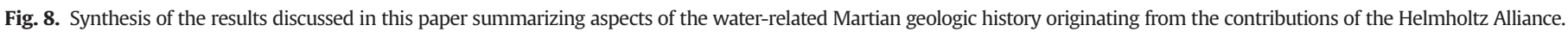

processes that rely on liquid water. Thus, modeling of flow transport processes revealed that the formation of deltas on Mars geologically requires only brief timespans (Kleinhans et al., 2010) and, based on discharge estimates, the formation of erosional valleys also needs less than a million years and most likely occurred only episodically (e.g., Irwin et al., 2005a; Jaumann et al., 2005, 2010; Hoke et al., 2011).

Mineral assemblages and stratigraphic relationships of phyllosilicates suggest a development primarily under a neutral to alkaline environment during the Noachian Epoch under a subarid climate. However weathering and chemical alteration products indicate multiple alteration, erosion and aqueous episodes that at least provide temporally aqueous environments including hydrothermal conditions.

Recently formed gullies and fans might have experienced even shorter periods of liquid water (minutes to hours), as shown by the identification of debris flow deposits that were formed by short-lived high-energy mass-wasting events (Reiss et al., 2010). However, most gullies show morphological characteristics, which indicate that they were formed by repeated flow events involving fluvial-dominated processes, such as snow deposits melting during high-obliquity phases (Reiss et al., 2010). The surface of Mars shows many landforms that resemble cold-climate features on Earth. Permafrost on Earth is known to host rich habitats containing cold-adapted microbial communities. Permafrost environments on Mars might represent habitable zones if liquid water is present, e.g., as a consequence of freeze-thaw cycles. However, the results of the Alliance work indicate that scenarios without liquid water might also account for many of the observed morphological phenomena that are analogous to terrestrial permafrost landforms (Ulrich et al., 2010; Hauber et al., 2011a,b).

The water- and ice-related environments on Mars are potential habitable places with respect to the fundamental environmental factor that requires at least episodic access to liquid water. Even with no adequate global climatic conditions, such as a long lasting warm and wet Mars, water- and ice-related surface processes occurred on an episodic timescale. However, the duration of the episodically appropriate conditions seems to be restricted to geologically relatively short periods.

\section{Acknowledgments}

This research has been supported by the Helmholtz Association through the research alliance "Planetary Evolution and Life". We acknowledge the detailed reviews of two anonymous reviewers that significantly improved this paper. We also appreciate the graphical support from Joana Voigt.

\section{References}

Adams, K.D., Wesnousky, S.G., 1988. Shoreline processes and the age of the Lake Lahontan highstand in the Jessup embayment, Nevada. Geol. Soc. Am. Bull. 110 1318-1332.

Adeli, S., Hauber, E., Le Deit, L., Jaumann, R., 2012. Sedimentary evolution of the Eridania paleolake in the atlantis chaos basin, Terra Sirenum. LPI Contributions no. 1680 , id 7047.

Adeli, S., Hauber, E., Le Deit, L., Jaumann, R., 2013, Different phylloslicate-rich materials on the Terra Sirenum region, Mars. LPI Contributions no. 1719, id 2752

Altheide, T.S., Chevrier, V.F., Noe Dobrea, E.Z., 2010. Mineralogical characterization of acid weathered phyllosilicates with implications for secondary martian deposits. Geochim. Cosmochim. Acta 74 (21), 6232-6248, http://dx.doi.org/ 10.1016/j.gca.2010.08.005.

Anderson, D.M., Gatto, L.W., Ugolini, F.C., 1972. An Antarctic analog of Martian permafrost terrain. Antarct. J. U. S. 7, 114-116.

Andrews-Hanna, J.C., Phillips, R.J., 2007. Hydrological modeling of outflow channels and chaos regions on Mars. J. Geophys. Res.: Planets 112 (E8), E08001, http://dx. doi.org/10.1029/2006je002881.

Andrews-Hanna, J.C., Phillips, R.J., Zuber, M.T., 2007. Meridiani Planum and the global hydrology of Mars. Nature 446, 163-166.

Andrews-Hanna, J.C., Lewis, K.W., 2011. Early Mars hydrology: 2. Hydrological evolution in the Noachian and Hesperian epochs. J. Geophys. Res. (Planets) 116 2007, http://dx.doi.org/10.1029/2010JE003709. 
Annex, A.M., Howard, A. D., 2011. Phyllosilicates related to exposed knobs in Sirenum Fossae, Ariadnes Colles. In: Proceedings of Lunar and Planetary Institute Science Conference Abstracts (edited), p. 1577.

Ansan, V., Mangold, N., 2006. New observations of Warrego Valles, Mars: evidence for precipitation and surface runoff. Planet. Space Sci. 54, 219-242, http://dx. doi.org/10.1016/j.pss.2005.12.009.

Ansan, V., et al., 2011. Stratigraphy, mineralogy, and origin of layered deposits inside Terby crater, Mars. Icarus 211, 273-304, http://dx.doi.org/10.1016/j. icarus.2010.09.011.

Baker, V.R., Strom, R.G., Gulick, V.C., Kargel, J.S., Komatsu, G., 1991. Ancient oceans, ice sheets and the hydrological cycle on Mars. Nature 352, 589-594, http://dx. doi.org/10.1038/352589a0.

Baker, V.R., Carr, M.H., Gulick, V.C., Williams, C.R., Marley, M.S., 1992. Channels and valley networks. In: Kieffer, H.H., Jakosky, B.M., Snyder, C.W., Matthews, M.S. (Eds.), Mars. University of Arizona Press, Tuscon, pp. 493-522

Baker, V.R., 2001. Water and the Martian landscape. Nature 412, 228-236.

Baldridge, A.M., Hook, S.J., Crowley, J.K., Marion, G.M., Kargel, J.S., Michalski, J.L. Thomson, B.J., de Souza Filho, C.R., Bridges, N.T., Brown, A.J., 2009. Contemporaneous deposition of phyllosilicates and sulfates: using Australian acidic saline lake deposits to describe geochemical variability on Mars. Geophys. Res. Lett. 36, 19201, http://dx.doi.org/10.1029/2009GL040069.

Balme, M.R., Mangold, N., Baratoux, D., Costard, F., Gosselin, M., Masson, P., Pinet, P. Neukum, G., 2006. Orientation and distribution of recent gullies in the southern hemisphere of Mars: observations from High Resolution Stereo Camera/Mars Express (HRSC/MEX) and Mars Orbiter Camera/Mars Global Surveyor (MOC/MGS) data. J. Geophys. Res. 111, E05001, http://dx.doi.org/10.1029/ 2005JE002607.

Barnhart, C.J., Howard, A.D., Moore, J.M., 2009. Long-term precipitation and latestage valley network formation: Landform simulations of Parana Basin, Mars. J. Geophys. Res. (Planets) 114, 01003, http://dx.doi.org/10.1029/2008JE003122.

Bibring, J.-P., et al., 2004. Perennial water ice identified in the south polar cap of Mars. Nature 428, 627-630.

Bibring, J.-P., et al., 2006. Global mineralogical and aqueous mars history derived from OMEGA/Mars Express Data. Science 312, 400-404

Bibring, J.-P., et al., 2007. Coupled ferric oxides and sulfates on the Martian surface. Science 317, 1206-1210.

Bishop, J.L., et al., 2008. Phyllosilicate diversity and past aqueous activity revealed at Mawrth Vallis, Mars. Science 321, 830-833, http://dx.doi.org/10.1126/ science.1159699.

Bishop, J.L. et al., 2009. Mineralogy of Juventae Chasma: sulfates in the light-toned mounds, mafic minerals in the bedrock, and hydrated silica and hydroxylated ferric sulfate on the plateau. J. Geophys. Res.: Planets 114 (E2), E00D09, http://dx. doi.org/10.1029/2009je003352.

Bishop, J.L., Tirsch, D., Tornabene, L.L., McGuire, P.C., Ody, A., Poulet, F., Hash, C. Mustard, J.F., Jaumann, R., and Murchie, S.L., 2012, Fe/Mg-smectite, carbonate and Al-Smectite in Ancient Aqueous Outcrops at Libya Montes and their association with fluvial features and Mafic Rocks, In: Lunar and Planetary Institute Science Conference Abstracts (edited), p. 2330

Bishop, J.L., et al., 2013. Mineralogy and morphology of geologic units at Libya Montes, Mars: ancient aqueously derived outcrops, mafic flows, fluvial features and impacts. J. Geophys. Res. (Planets) 118, 487-513, http://dx.doi.org/10.1029/ 2012JE004151.

Bleamaster, L.F., Crown, D.A., 2005. Mantle and gully associations along the walls of Dao and Harmakhis Valles, Mars. Geophys. Res. Lett. 32, L20203, http://dx.doi. org/10.1029/2005GL023548.

Bouley, S., Ansan, V., Mangold, N., Masson, P., Neukum, G., 2009. Fluvial morphology of Naktong Vallis, Mars: a late activity with multiple processes. Planet. Space Sci. 57, 982-999, http://dx.doi.org/10.1016/j.pss.2009.01.015.

Bouley, S., Craddock, R.A., Mangold, N., Ansan, V., 2010. Characterization of fluvial activity in Parana Valles using different age-dating techniques. Icarus 207, 686-698, http://dx.doi.org/10.1016/j.icarus.2009.12.030.

Bradley, W.C., Griggs, G.B., 1976. Form, genesis, and deformation of centra California wave-cut platforms. Geol. Soc. Am. Bull. 87, 433-449, http://dx.doi org $/ 10.1130 / 0016-7606(1976) 87<433:$ FGADOC $>2.0 . C O ; 2$

Bridges, J.C., Schwenzer, S.P., 2012. The nakhlite hydrothermal brine on Mars. Earth Planet. Sci. Lett. 359-360, 117-123, http://dx.doi.org/10.1016/j. epsl.2012.09.044.

Buczkowski, D.L, Murchie, S., Clark, R.N., Seelos, K., Seelos, F., Malaret, E., Hash, C. 2010. Investigation of an Argyre basin ring structure using Mars reconnaissance orbiter/compact reconnaissance imaging spectrometer for Mars. J. Geophys. Res.: Planets 115 (E12), E12011, http://dx.doi.org/10.1029/2009je003508.

Byrne, S., et al., 2009. Distribution of mid-latitude ground ice on Mars from new impact craters. Science 325 (5948), 1674-1676, http://dx.doi.org/10.1126 science.1175307.

Cabrol, N.A., Grin, E.A., 1999. Distribution, classification, and ages of Martian impact crater lakes. Icarus 142, 160-172.

Cabrol, N.A., Grin, E.A., Newsom, H.E., Landheim, R., McKay, C.P., 1999. Hydrogeologic evolution of Gale crater and its relevance to the exobiologica exploration of Mars. Icarus 139, 235-245, http://dx.doi.org/10.1006/icar 1999.6099.

Cabrol, N.A., Grin, E.A., 2001. The Evolution of Lacustrine Environments on Mars: is mars only hydrologically dormant? Icarus 149 (2), 291-328, http://dx.doi.org 10.1006/icar.2000.6530.

Cabrol, N.A., Grin, E.A., 2002. Overview on the formation of paleolakes and ponds on Mars. Glob. Planet. Change 35 (3-4), 199-219, http://dx.doi.org/10.1016/ S0921-8181(02)00127-3.
Carr, M.H., 1979. Formation of Martian flood features by release of water from confined aquifers. J. Geophys. Res. 84, 2995-3007.

Carr, M.H., 1995. The Martain drainage system and the origin of valley networks and fretted channels. J. Geophys. Res. 100, 7479-7507.

Carr, M.H., Chuang, F.C., 1997. Martian drainage densities. J. Geophys. Res. 102, 9145-9152, http://dx.doi.org/10.1029/97JE00113.

Carr, M.H., Malin, M.C., 2000. Meter-scale characteristics of Martian channels and valleys. Icarus 146, 366-386.

Carr, M.H., 2001. Mars global surveyor observations of Martian fretted terrain. J. Geophys. Res. 106, 23571-23594.

Carr, M.H., Head, J.W., 2003. Basal melting of snow on early Mars: a possible origin of some valley networks. Geophys. Res. Lett. 30, 2245, http://dx.doi.org/ 10.1029/2003GL018575.

Carr, M.H., Head, J.W., 2010. Geologic history of Mars. Earth Planet. Sci. Lett. 294 (3-4), 185-203, http://dx.doi.org/10.1016/j.epsl.2009.06.042.

Carr, M.H., 2012. The fluvial history of Mars. Philos. Trans. R. Soc. A 370, 2193-2215, http://dx.doi.org/10.1098/rsta.2011.0500.

Carter, J., Poulet, F., Bibring, J.-P., Murchie, S., 2010. Detection of hydrated silicates in crustal outcrops in the northern plains of Mars. Science 328, 1682, http://dx. doi.org/10.1126/science.1189013.

Carter, J., Poulet, F., Bibring, J.-P., Mangold, N., Murchie, S., 2013. Hydrous minerals on Mars as seen by the CRISM and OMEGA imaging spectrometers: updated global view. J. Geophys. Res.: Planets 118, 831-858, http://dx.doi.org/10.1029/ 2012JE004145.

Cernicharo, J., Crovisier, J., 2005. Water in space: the water world of ISO. Space Sci. Rev. 119 (1-4), 29-69, http://dx.doi.org/10.1007/s11214-005-8058-x.

Chamley, H., 1989. Clay Sedimentology. Springer, New York (623 pp.)

Chapman, M.G., Tanaka, K.L., 2001. Interior trough deposits on Mars: subice volcanoes? J. Geophys. Res.: Planets 106 (E5), 10087-10100, http:/dx.doi.org/ 10.1029/2000je001303.

Christensen, P.R., 2003. Formation of recent martian gullies through melting of extensive water-rich snow deposits. Nature 422, 45-48.

Christensen, P.R., Bandfield, J.L., Rogers, A.D., Glotch, T.D., Hamilton, V.E., Ruff, S.W., Wyatt, M.B., 2008. Global mineralogy mapped from the Mars Global Surveyor Thermal Emission Spectrometer. In: Christensen, P.R. (Ed.), The Martian Surface. Cambridge University Press, Cambridge, pp. 193-220

Clifford, S.M., 1993. A model for the hydrologic and climatic behavior of water on Mars. J. Geophys. Res. 98, 10973, http://dx.doi.org/10.1029/93JE00225.

Clifford, S.M., Parker, T.J., 2001. The evolution of the Martian hydrosphere: implications for the fate of a Primordial Ocean and the current state of the northern plains. Icarus 154, 40-79, http://dx.doi.org/10.1006/icar.2001.6671.

Clifford, S.M., Parker, T.J., Mouginot, J., Pommerol, A., Beck, P., and Kofman, W., 2012, Evidence and arguments for an early Martian Ocean. LPI Contributions no. 1680, id 7082.

Colaprete, A., Toon, O.B., 2003. Carbon dioxide clouds in an early dense Martian atmosphere. J. Geophys. Res. 108 (6-1), 5025, http://dx.doi.org/10.1029/ 2002JE001967.

Costard, F., Forget, F., Mangold, N., Peulvast, J.P., 2002. Formation of recent Martian debris flows by melting of near-surface ground ice at high obliquity. Science 295, 110-113.

Craddock, R.A., Howard, A.D., 2002. The case for rainfall on a warm, wet early Mars. J. Geophys. Res. (Planets) 107, 5111, http://dx.doi.org/10.1029/2001JE001505.

Crumpler, L.S., Tanaka, K.L., 2003. Geology and MER target site characteristics along the southern rim of Isidis Planitia, Mars. J. Geophys. Res. (Planets) 108, 8080, http://dx.doi.org/10.1029/2002JE002040.

Cull, S., Arvidson, R.E., Mellon, M.T., Wiseman, S.M., Clark, R.N., Titus, T.N., Morris, R.V., McGuire, P.C., 2010. Seasonal $\mathrm{H}_{2} \mathrm{O}$ and $\mathrm{CO}_{2}$ ice cycles at the Mars Phoenix landing site: 1. Prelanding CRISM and HiRISE observations. J. Geophys. Res. (Planets) 115 E00D16, http://dx.doi.org/10.1029/2009JE003340.

Davila, A.F., Gross, C., Marzo, G.A., Fairén, A.G., Kneissl, T., McKay, C.P., Dohm, J.M., 2011. A large sedimentary basin in the Terra Sirenum region of the southern highlands of Mars. Icarus 212 (2), 579-589, http://dx.doi.org/10.1016/j. icarus.2010.12.023

Dehouck, E., Mangold, N., Le Mouélic, S., Ansan, V., Poulet, F., 2010. Ismenius Cavus, Mars: a deep paleolake with phyllosilicate deposits. Planet. Space Sci. 58 (6), 941-946, http://dx.doi.org/10.1016/j.pss.2010.02.005.

Di Achille, G., Ori, G.G., Reiss, D., 2007. Evidence for late Hesperian lacustrine activity in Shalbatana Vallis, Mars. J. Geophys. Res. (Planets) 112, 07007.

Di Achille, G., Hynek, B.M., 2010. Ancient ocean on Mars supported by global distribution of deltas and valleys. Nat. Geosci. 3, 459-463.

Dickson, J., Head, J.W., Kreslavsky, M.A., 2007. Martian gullies in the southern midlatitudes of Mars: evidence for climate-controlled formation of young fluvial features based upon local and global topography. Icarus 188, 315-323.

Diniega, S., Byrne, S., Bridges, N.T., Dundas, C.M., McEwen, A.S., 2011. Seasonality of present-day Martian dune-gully activity. Geology 38, 1047-1050, http://dx.doi. org/10.1130/G31287.1.

Dundas, C.M., Diniega, S., Hansen, C.J., Byrne, S., McEwen, A.S., 2012. Seasonal activity and morphological changes in martian gullies. Icarus 220, 124-143.

Dunne, T., 1980. Formation and controls of channel networks. Prog. Phys. Geogr. 4, 211-239.

Ehlmann, B.L., et al., 2009. Identification of hydrated silicate minerals on Mars using MRO-CRISM: geologic context near Nili Fossae and implications for aqueous alteration. J. Geophys. Res. (Planets) 114, E00D08, http://dx.doi.org/10.1029/ 2009JE003339. 
Ehlmann, B.L., Mustard, J.F., Murchie, S.L., Bibring, J.-P., Meunier, A., Fraeman, A.A., Langevin, Y., 2011. Subsurface water and clay mineral formation during the early history of Mars. Nature 479 (7371), 53-60, http://dx.doi.org/10.1038/ nature 10582 .

Ehlmann, B.L., Berger, G., Mangold, N., Michalski, J.R., Catling, D.C., Ruff, S.W., Chassefière, E., Niles, P.B., Chevrier, V., Poulet, F., 2013. Geochemical consequences of widespread clay mineral formation in Mars' ancient crust. Space Sci. Rev. 174, 329-364, http://dx.doi.org/10.1007/s11214-012-9930-0.

Erkeling, G., Reiss, D., Hiesinger, H., Jaumann, R., 2010. Morphologic, stratigraphic and morphometric investigations of valley networks in eastern Libya Montes, Mars: implications for the Noachian/Hesperian climate change. Earth Planet. Sci. Lett. 294, 291-305, http://dx.doi.org/10.1016/j.epsl.2009.08.008.

Erkeling, G., Hiesinger, H., Reiss, D., Hielscher, F.J., Ivanov, M.A., 2011. The stratigraphy of the Amenthes region, Mars: time limits for the formation of fluvial, volcanic and tectonic landforms. Icarus 215, 128-152, http://dx.doi.org/ 10.1016/j.icarus.2011.06.041.

Erkeling, G., Reiss, D., Hiesinger, H., Poulet, F., Carter, J., Ivanov, M.A., Hauber, E., Jaumann, R., 2012. Valleys, paleolakes and possible shorelines at the Libya Montes/Isidis boundary: implications for the hydrologic evolution of Mars. Icarus 219, 393-413, http://dx.doi.org/10.1016/j.icarus.2012.03.012.

Everdingen, R.O.V., 2005. Multi-Language Glossary of Permafrost and Related Ground-Ice Terms. International Permafrost Association, University of Calgary, Calgary, Canada. Available at: 〈http://nsidc.org/fgdc/glossary

Fairén, A.G., et al., 2010. Toro crater: the case for hesperian phyllosilicates on Mars. LPI Contributions no. 1538, id 5588.

Fassett, C.I., Head, J.W., 2005. Fluvial sedimentary deposits on Mars: ancient deltas in a crater lake in the Nili Fossae region. Geophys. Res. Lett. 32, 14201, http://dx. doi.org/10.1029/2005GL023456.

Fassett, C.I., Ehlmann, B.L., Head, J.W., Mustard, J.F., Schon, S.C., Murchie, S.L., 2007. Sedimentary Fan Deposits in Jezero Crater Lake, in the Nili Fossae Region, Mars: Meter-scale Layering and Phyllosilicate-Bearing Sediments, AGU Fall Meeting Abstracts, 13, p. 1562.

Fassett, C.I., Head, J.W., 2008a. Valley network-fed, open-basin lakes on Mars: distribution and implications for Noachian surface and subsurface hydrology. Icarus 198, 37-56.

Fassett, C.I., Head, J.W., 2008b. The timing of martian valley network activity: constraints from buffered crater counting. Icarus 195, 61-89.

Fassett, C.I., Head, J.W., 2011. Sequence and timing of conditions on early Mars. Icarus 211, 1204-1214.

Feldman, W.C., et al., 2002. Global distribution of neutrons from Mars: results from Mars Odyssey. Science 297, 75-78.

Fueten, F., et al., 2010. Structural analysis of interior layered deposits in Northern Coprates Chasma, Mars. Earth Planet. Sci. Lett. 294 (3-4), 343-356, http://dx. doi.org/10.1016/j.epsl.2009.11.004.

Gaidos, E., Marion, G., 2003. Geological and geochemical legacy of a cold early Mars. J. Geophys. Res. 108 (E6), 9-11, http://dx.doi.org/10.1029/2002JE002000.

Gallagher, C.J., Balme, M.R., Conway, S.J., Grindrod, P.M., 2011. Sorted clastic stripes, lobes and associated gullies in high-latitude craters on Mars: landforms indicative of very recent, polycyclic ground-ice thaw and liquid flows. Icarus 211, 458-471, http://dx.doi.org/10.1016/j.icarus.2010.09.010.

Gardiner, V., Gregory, K.J., 1982. Drainage density in rainfall-runoff modelling. In: Singh, V.P. (Ed.), Rainfall-Runoff Relationships. Water Research Publications, Fort Collins, Colorado, pp. 449-476

Gaudin, A., Dehouck, E., Mangold, N., 2011. Evidence for weathering on early Mars from a comparison with terrestrial weathering profiles. Icarus 216, 257-268, http://dx.doi.org/10.1016/j.icarus.2011.09.004.

Gendrin, A., 2005. Sulfates in the Martian layered terrains: the OMEGA/Mars express view. Science 307, 1587-1591, http://dx.doi.org/10.1126/science.1109509.

Ghatan, G.J., Zimbelman, J.R., 2006. Paucity of candidate coastal constructional landforms along proposed shorelines on Mars: implications for a northern lowlands-filling ocean. Icarus 185, 171-196, http://dx.doi.org/10.1016/j.icarus. 2006.06.007.

Glotch, T.D., Christensen, P.R., 2005. Geologic and mineralogic mapping of Aram Chaos: evidence for a water-rich history. J. Geophys. Res. (Planets) 110, 9006, http://dx.doi.org/10.1029/2004JE002389.

Glotch, T.D., Rogers, A.D., 2007. Evidence for aqueous deposition of hematite- and sulfate-rich light-toned layered deposits in Aureum and Iani Chaos, Mars. J. Geophys. Res. (Planets) 112, 6001, http://dx doi.org/101029/2006JE002863.

Glotch, T.D., Bandfield, J.L., Tornabene, L.L., Jensen, H.B., Seelos, F.P., 2010. Distribution and formation of chlorides and phyllosilicates in Terra Sirenum, Mars. Geophys. Res. Lett. 37 (16), L16202, http://dx.doi.org/10.1029/2010gl044557.

Goldspiel, J.M., Squyres, S.W., 2000. Groundwater sapping and valley formation on Mars. Icarus 148, 176-192.

Grant, J.A., 2000. Valley formation in Margaritifer Sinus, Mars, by precipitationrecharged ground-water sapping. Geology 28, 223, http://dx.doi.org/10.1130/ 0091-7613(2000)28<223:VFIMSM > 2.0.CO;2

Grant, J.A., Irwin, R.P., Grotzinger, J.P., Milliken, R.E., Tornabene, L.L., McEwen, A.S., Weitz, C.M., Squyres, S.W., Glotch, T.D., Thomson, B.J., 2008. HiRISE imaging of impact megabreccia and sub-meter aqueous strata in Holden Crater, Mars. Geology 36, 195-198, http://dx.doi.org/10.1130/G24340A.1.

Grant, J.A., Irwin, R.P., Wilson, S.A., Buczkowski, D., Siebach, K., 2011. A lake in Uzboi Vallis and implications for Late Noachian-Early Hesperian climate on Mars. Icarus 212, 110-122, http://dx.doi.org/10.1016/j.icarus.2010.11.024.

Greeley, R., Foing, B.H., McSween, H.Y., Neukum, G., Pinet, P., van Kan, M., Werner, S.C., Williams, D.A., Zegers, T.E., 2005. Fluid lava flows in Gusev crater, Mars. J. Geophys. Res.: Planets 110 (E5), E05008, http://dx.doi.org/10.1029/2005je002401.
Gross, C., Sowe, M., Wendt, L., Bishop, J.L., Fairén, A.G., 2012. Phyllosilicates in Bamberg Crater, Mars. In: Proceedings of Lunar and Planetary Institute Science Conference Abstracts (edited), p. 2356.

Grotzinger, J.P., et al., 2012. Mars science laboratory mission and science investigation. Space Sci. Rev. 170 (1-4), 5-56, http://dx.doi.org/10.1007/s11214-0129892-2.

Gulick, V.C., Baker, V.R., 1990. Origin and evolution of valleys on Martian volcanoes J. Geophys. Res. 95, 14325-14344, http://dx.doi.org/10.1029/JB095iB09p14325.

Haltigin, T., Pollard, W. Diutilleul, P., 2010. Comparison of ground- and aerial-based approaches for quantifying polygonalterrain network geometry on Earth and Mars via spatial point pattern analysis. Planet. Space Sci. 58, 1636-1649, http://dx.doi.org/10.1016/j.pss.2010.08.008.

Harrison, K.P., Grimm, R.E., 2005. Groundwater-controlled valley networks and the decline of surface runoff on early Mars. J. Geophys. Res. (Planets) 110, E12S16, http://dx.doi.org/10.1029/2005JE002455.

Hauber, E., van Gasselt, S., Chapman, M.G. Neukum, G., 2008. Geomorphic evidence for former lobate debris aprons at low latitudes on Mars: indicators of the Martian paleoclimate. J. Geophys. Res. (Planets) 113, 02007.

Hauber, E., Gwinner, K., Kleinhans, M., Reiss, D., di Achille, G., Ori, G.-G., Scholten, F., Marinangeli, L., Jaumann, R., Neukum, G., 2009. Sedimentary deposits in Xanthe Terra: implications for the ancient climate on Mars. Planet. Space Sci. 57, 944-957, http://dx.doi.org/10.1016/j.pss.2008.06.009.

Hauber, E., et al., 2011a. Periglacial Landscapes on Svalbard: Terrestrial Analogues for Cold-Climate Landforms on Mars. 483. Geological Society of America, pp. 177-201 (special paper)

Hauber, E., et al., 2011b. Landscape evolution in Martian mid-latitude regions: Insights from analogous periglacial landforms in Svalbard. In: Balme, M.R., Bargery, A.S., Gallagher, C.J., Gupta, S. (Eds.), Martian Geomorphology. Geological Society, London, pp. 111-131 (special paper 356)

Hauber, E., Platz, T., Reiss, D., Le Deit, L., Kleinhans, M.G., Marra, W.A., de Haas, T. Carbonneau, P., 2013. Asynchronous formation of Hesperian and Amazonianaged deltas on Mars and implications for climate. J. Geophys. Res.: Planets 118 (7), 1529-1544, http://dx.doi.org/10.1002/jgre.20107.

Head, J.W., Hiesinger, H., Ivanov, M.A., Kreslavsky, M.A., Pratt, S., Thomson, B.J. 1999. Possible ancient oceans on Mars: evidence from Mars Orbiter Laser Altimeter data. Science 286, 2134-2137.

Head, J.W., Mustard, J.F., Kreslavsky, M.A., Milliken, R.E., Marchant, D.R., 2003a Recent ice ages on Mars. Nature 426, 797-802, http://dx.doi.org/10.1038/ nature02114.

Head, J.W., Wilson, L., Mitchell, K.L., 2003b. Generation of recent massive water floods at Cerberus Fossae, Mars by dike emplacement, cryospheric cracking, and confined aquifer groundwater release. Geophys. Res. Lett. 30, 1577, http: //dx.doi.org/10.1029/2003GL017135.

Head, J.W., Marchant, D.R., Ghatan, G.J., 2004. Glacial deposits on the rim of a Hesperian-Amazonian outflow channel source trough: Mangala Valles, Mars. Geophys. Res. Lett. 31, 10701, http://dx.doi.org/10.1029/2004GL020294.

Head, J.W., et al., 2005. Tropical to mid-latitude snow and ice accumulations, flow and glaciations on Mars. Nature 434, 346-351.

Head, J.W., Marchant, D.R., Agnew, M.C., Fassett, C.I., Kreslavsky, M.A., 2006 Extensive valley glacier deposits in the northern mid-latitudes of Mars evidence for Late Amazonian obliquity-driven climate change. Earth Planet. Sci. Lett. 241, 663-671.

Head, J.W., Marchant, D.R., Kreslavsky, M.A., 2008. Formation of gullies on Mars: link to recent climate history and insolation microenvironments implicate surface water flow origin. Proc. Natl. Acad. Sci. USA 108, 18725636, http://dx. doi.org/10.1073/pnas.0803760105.

Hoke, M.R. T., Hynek, B.M., 2009. Roaming zones of precipitation on ancient Mars as recorded in valley networks. J. Geophys. Res. (Planets) 114, 08002, http://dx.doi org/10.1029/2008JE003247.

Hoke, M.R. T., Hynek, B.M., Tucker, G.E., 2011. Formation timescales of large Martian valley networks. Earth Planet. Sci. Lett. 312 (1-2), 1-12, http://dx.doi.org/ 10.1016/j.epsl.2011.09.053.

Horton, R.E., 1945. Erosional development of streams and their drainage basins hydrophysical approach to quantitative morphology. Geol. Soc. Am. Bull. 56, 275-370.

Hou, J., Han, M., Ollier, C.D., 1997. A morphometric method to determine neotectonic activity of the Weihe basin in northwestern China. Episodes 20 (2), 95-99.

Howard, A.D., 2004. Scarp-bounded benches in Gorgonum Chaos, Mars: formed beneath an ice-covered lake? Geophys. Res. Lett. 31 (1), L01702, http://dx.doi. org/10.1029/2003gl018925.

Hynek, B.M., Phillips, R.J., 2001. The Role of Water in the Evolution of the Enigmatic Arabia Terra, Mars. In: Proceeedings of AGU Fall Meeting Abstracts, vol. 22, p. 0538.

Hynek, B.M., Arvidson, R.E., Phillips, R.J., 2002. Geologic setting and origin of Terra Meridiani hematite deposit on Mars. J. Geophys. Res.: Planets 107 (E10), 18-11-18-14, http://dx.doi.org/10.1029/2002je001891.

Hynek, B.M., Beach, M., Hoke, M.R. T., 2010. Updated global map of Martian valley networks and implications for climate and hydrologic processes. J. Geophys. Res. (Planets) 115, 9008, http://dx.doi.org/10.1029/2009JE003548.

Irwin, R.P., 2004. Geomorphology of Ma'adim Vallis, Mars, and associated paleolake basins. J. Geophys. Res. 109 (E12), E12009, http://dx.doi.org/10.1029/ 2004je002287.

Irwin, R.P., Craddock, R.A., Howard, A.D., 2005a. Interior channels in Martian valley networks: discharge and runoff production. Geology 33, 489-492, http://dx. doi.org/10.1130/G21333.1. 
Irwin, R.P., Howard, A.D., Craddock, R.A., Moore, J.M., 2005b. An intense terminal epoch of widespread fluvial activity on early Mars: 2. Increased runoff and paleolake development. J. Geophys. Res. (Planets) 110, E12S15, http://dx.doi. org/10.1029/2005JE002460.

Irwin, R.P., Howard, A.D., Craddock, R.A., 2008. Fluvial valley networks on Mars. In: Rice, S.P. Roy, A.G., Rhoads, B.L. (Eds.), River Confluences, Tributaries and the Fluvial Network. JohnWiley \& Sons, Ltd, Chichester, New York

Ivanov, M.A., Hiesinger, H., Erkeling, G., Hielscher, F.J., Reiss, D., 2012. Major episodes of geologic history of Isidis Planitia on Mars. Icarus 218, 24-46, http://dx.doi.org/ 10.1016/j.icarus.2011.11.029.

Jacobshagen, V., Arndt, J., Götze, H.-J., Mertmann, D., Wallfass, C.M., 2000 Einführung in die geologischen Wissenschaften. Verlag Eugen Ulmer, Stuttgart

Jakosky, B.M., Phillips, R.J., 2001. Mars' volatile and climate history. Nature 412 $237-244$

Jaumann, R., et al., 2005. Interior channels in Martian valleys: constraints on fluvial erosion by measurements of the Mars Express High Resolution Stereo Camera. Geophys. Res. Lett. 32, 16203, http://dx.doi.org/10.1029/2005GL023415.

Jaumann, R., Nass, A., Tirsch, D., Reiss, D., Neukum, G., 2010. The Western Libya Montes Valley System on Mars: evidence for episodic and multi-genetic erosion events during the Martian history. Earth Planet. Sci. Lett. 294 (3-4), 272-290, http://dx.doi.org/10.1016/j.epsl.2009.09.026.

Johnsson, A., Reiss, D., Hauber, E., Hiesinger, H., and Zanetti, M., (in press). Evidence for very recent melt-water and debris flow activity in gullies in a young midlatitude crater on Mars. Icarus, http://dx.doi.org/10.1016/j.icarus.2014.03.005.

Johnsson, A., Reiss, D., Hauber, E., Zanetti, M., Hiesinger, H., Johansson, L., Olvmo, M., 2012. Periglacial mass-wasting landforms on Mars suggestive of transient liquid water in the recent past: insights from solifluction lobes on Svalbard Icarus 218 (1), 489-505, http://dx.doi.org/10.1016/j.icarus.2011.12.021.

Kargel, J.S., Strom, R.G., 1992. Ancient glaciation on Mars. Geology 20, 3-7, http: /ldx.doi.org/10.1130/0091-7613(1992)020 < 0003:AGOM > 2.3.CO:2.

Kasting, J.F., 1991. CO 2 condensation and the climate of early Mars. Icarus 94, 1-13.

Kasting, J.F., Whitmire, D.P., Reynolds, R.T., 1993. Habitable zones around main sequence stars. Icarus 101, 108-128, http://dx.doi.org/10.1006/icar.1993.1010.

Keller, H. U.. et al., 2009. Physical Properties of the Icy Soil at the Phoenix Landing Site. Paper Presented at Lunar and Planetary Institute Science Conference Abstracts, March 1, 2009.

Kite, E.S., Michaels, T.I., Rafkin, S., Manga, M., Dietrich, W.E., 2011. Localized precipitation and runoff on Mars. J. Geophys. Res. (Planets) 116, 7002, http: //dx.doi.org/10.1029/2010JE003783.

Kleinhans, M.G, van de Kasteele, H.E. Hauber, E, 2010. Palaeoflow reconstruction from fan delta morphology on Mars. Earth Planet. Sci. Lett. 294, 378-392, http: //dx.doi.org/10.1016/j.epsl.2009.11.025.

Kneissl, T., Reiss, D., van Gasselt, S., Neukum, G., 2010. Distribution and orientation of northern-hemisphere gullies on Mars from the evaluation of HRSC and MOCNA data. Earth Planet. Sci. Lett. 294, 357-367, http://dx.doi.org/10.1016/j. epsl.2009.05.018.

Kochel, R.C., Howard, A.D., 1985, Groundwater Sapping and Ancient Valley Networks on Mars. Paper Presented at Water on Mars. A Lunar and Planetary Institute Workshop, Lunar and Planetary Institute. LPI Technical Report 85-03, Houston, n/a 1, 1985

Komatsu, G., Di Achille, G., Popa, C., Di Lorenzo, S., Rossi, A.P., Rodriguez, J.A. P., 2009. Paleolakes, paleofloods, and depressions in Aurorae and Ophir Plana, Mars: connectivity of surface and subsurface hydrological systems. Icarus 201 (2), 474-491, http://dx.doi.org/10.1016/j.icarus.2009.01.010.

Kreslavsky, M.A., Head, J.W., 2002. Fate of outflow channel effluents in the northern lowlands of Mars: the Vastitas Borealis formation as a sublimation residue from frozen ponded bodies of water. J. Geophys. Res. (Planets) 107, 5121, http://dx. doi.org/10.1029/2001JE001831.

Laskar, J., Levrard, B., Mustard, J.F., 2002. Orbital forcing of the martian polar layered deposits. Nature 419, 375-377.

Laskar, J., Correia, A.C. M., Gastineau, M., Joutel, F., Levrard, B., Robutel, P., 2004 Long term evolution and chaotic diffusion of the insolation quantities of Mars. Icarus 170, 343-364

Lasue, J., Mangold, N., Hauber, E., Clifford, S.M., Feldman, W., Gasnault, O., Grima, C. Maurice, S., Mousis, O., 2013. Quantitative assessments of the martian hydrosphere. Space Sci. Rev. 174, 155-212, http://dx.doi.org/10.1007/s11214-012-9946-5.

Le Deit, L., Bourgeois, O., Mège, D., Hauber, E., Le Mouélic, S., Massé, M., Jaumann, R. Bibring, J.-P., 2010. Morphology, stratigraphy, and mineralogical composition of a layered formation covering the plateaus around Valles Marineris, Mars: implications for its geological history. Icarus 208, 684-703, http://dx.doi.org/ 10.1016/j.icarus.2010.03.012.

Le Deit, L., Flahaut, J., Quantin, C., Hauber, E., Mège, D., Bourgeois, O., Gurgurewicz, J. Massé, M., Jaumann, R., 2012. Extensive surface pedogenic alteration of the Martian Noachian crust suggested by plateau phyllosilicates around Valles Marineris. J. Geophys. Res.: Planets 117 (E3), E00J05, http://dx.doi.org/10.1029/ 2011 je003983.

Le Deit, L., Hauber, E., Fueten, F., Pondrelli, M., Rossi, R.P., Jaumann, R., 2013. Sequence of infilling events in Gale Crater, Mars: Results from morphology, stratigraphy, and mineralogy. J. Geophys. Res. (Planets) 118, 2439-2473, http:// dx.doi.org/10.1002/2012JE004322.

Lefort, J., Correia, A.C. M., Gastineau, M., Joutel, F., Levrard, B., Robutel, P., 2010 Scalloped terrain in Peneus and Amphitrites Paterae region of Mars as observed by HiRISE. Icarus 205, 259-268, http://dx.doi.org/10.1016/j.icarus.2009.06.005.

Leverington, D.W., 2006. Volcanic processes as alternative mechanisms of landform development at a candidate crater-lake site near Tyrrhena Patera, Mars. J. Geophys. Res. (Planets) 111, 11002, http://dx.doi.org/10.1029/2004JE002382.
Levy, J., Head, J.W., Marchant, D.R., 2011. Gullies, polygons and mantles in Martian permafrost environments: cold desert landforms and sedimentary processes during recent Martian geological history. In: Marttini, I.P., French, H.M., Reérez Alberti, A. (Eds.), Ice-Marginal and Periglacial Processes and Sediments, vol. 354. Geological Society Special Publications, London, pp. 167-182.

Levy, J.S., Head, J.W., Marchant, D.R., 2009. Thermal contraction crack polygons on Mars: classification, distribution, and climate implications from HiRISE observations. J. Geophys. Res. 114, E01007, http://dx.doi.org/10.1029/2008JE003273.

Lichtenberg, K.A., et al., 2010. Stratigraphy of hydrated sulfates in the sedimentary deposits of Aram Chaos, Mars. J. Geophys. Res. (Solid Earth) 115, E00D17, http://dx. doi.org/10.1029/2009JE003353.

Loizeau, D., et al., 2007. Phyllosilicates in the Mawrth Vallis region of Mars. J. Geophys. Res. (Planets), 112, http://dx.doi.org/10.1029/2006JE002877

Lucchitta, B.K., 1982. Ice sculpture in the Martian outflow channels. J. Geophys. Res. 87, 9951-9973.

Lucchitta, B.K., 2001. Antarctic ice streams and outflow channels on Mars. Geophys. Res. Lett. 28, 403-406.

Lucchitta, B.K., Anderson, D.M., 1979. Martian Outflow Channels Sculptured by Glaciers (Reports of Planetary Geology Program, 1979-1980) (pp. 271-273)

Lucchitta, B.K., Isbell, N.K., Howington-Kraus, A., 1994. Topography of Valles Marineris: implications for erosional and structural history. J. Geophys. Res. 99, 3783-3798, http://dx.doi.org/10.1029/93JE03095.

Magalhães, J.A., 1987. The Martian Headley Circulation: comparison of "viscous" model predictions to observations. Icarus 70, 442-468.

Malin, M.C., Carr, M.H., 1999. Groundwater formation of martian valleys. Nature 397, 589-591.

Malin, M.C., Edgett, K.S., 2000a. Evidence for recent groundwater seepage and surface runoff on Mars. Science 288, 2330-2335.

Malin, M.C., Edgett, K.S., 2000b. Sedimentary rocks of early Mars. Science 290, 1927-1937.

Malin, M.C., Edgett, K.S., 2003. Evidence for Persistent flow and aqueous sedimentation on early Mars. Science 302, 1931-1934.

Mangold, N., Quantin, C., Ansan, V., Delacourt, C., Allemand, P., 2004. Evidence for precipitation on mars from dendritic valleys in the Valles Marineris Area. Science 305, 78-81.

Mangold, N., 2005. High latitude patterned grounds on Mars: classification, distribution and climatic control. Icarus 174, 336-359.

Mangold, N., Kite, E.S., Kleinhans, M.G., Newsom, H., Ansan, V., Hauber, E., Kraal, E., Quantin, C., Tanaka, K., 2012. The origin and timing of fluvial activity at Eberswalde crater, Mars. Icarus 220 (2), 530-551, http://dx.doi.org/10.1016/j. icarus.2012.05.026.

Mangold, N., et al., 2013. Chemcam analysis of conglomerates at Bradbury Site, Mars. LPI Contributions no. 1719, id 1267.

Marchant, D.R., Lewis, A., Phillips, W.C., Moore, E.J., Souchez, R., Landis, G.P., 2002. Formation of patterned-ground and sublimation till over Miocene glacier ice in Beacon Valley, Antarctica. Geol. Soc. Am. Bull. 114, 718-730.

Marchant, D.R., Head, J.W., 2007. Antarctic Dry Valleys: microclimate zonation, variable geomorphic processes, and implications for assessing climate change on Mars. Icarus 192, 187-222.

Markiewicz, W. J., Kossacki, K. J., Keller, H. U., Hviid, S. F., Goetz, W., El Maarry, M. R., Mellon, M. T., Smith, P., 2009. Phoenix Mars Lander: Robotic Arm Camera images of the surface and sublimation of exposed Snow Queen water ice. In: Proceedings of European Planetary Science Congress 2009 (edited), p. 455.

MarsChannelWorkingGroup, 1983. Channels and valleys on Mars. Geol. Soc. Am. Bull 94 (4), 1035-1054.

Marzo, G.A., Davila, A.F., Tornabene, L.L., Dohm, J.M., Fairén, A.G., Gross, C., Kneissl, T., Bishop, J.L., Roush, T.L., McKay, C.P., 2010. Evidence for Hesperian impact-induced hydrothermalism on Mars. Icarus 208, 667-683.

McCauley, J.F., Carr, M.H., Cutts, J.A., Hartmann, W.K., Masursky, H., Milton, D.J., Sharp, R.P., Wilhelms, D.E., 1972. Preliminary mariner 9 report on the geology of Mars. Icarus 17 (2), 289-327.

McCauley, J.F., 1978. Geologic map of the Coprates Quadrangle of Mars, US Geological Survey Misc. Geol. Inv. Map I-896.

McEwen, A.S., et al., 2007. A closer look at water-related geologic activity on Mars. Science 317 (5845), 1706-1709, http://dx.doi.org/10.1126/science.1143987.

McEwen, A.S., Ojha, L., Dundas, C.M., Mattson, S.S., Byrne, S., Wray, J.J., Cull, S.C., Murchie, S.L., Thomas, N., Gulick, V.C., 2011. Seasonal flows on warm Martian slopes. Science 333 (6043), 740-743, http://dx.doi.org/10.1126/science.1204816.

McKay, C.P., Nedell, S.S., 1988. Are there carbonate deposits in the Valles Marineris, Mars? Icarus 73 (1), 142-148, http://dx.doi.org/10.1016/0019-1035(88)90088-7.

McKeown, N. K., Bishop, J. L., Noe Dobrea, E. Z., Ehlmann, B. L., Parente, M., Mustard, J. F., Murchie, S. L., Swayze, G. A., Bibring, J.-P., Silver, E. A., 2009, Characterization of phyllosilicates observed in the central Mawrth Vallis region, Mars, their potential formational processes, and implications for past climate. J. Geophys. R., 114. http://dx.doi.org/10.1029/2008je003301.

Michael, G.G., Neukum, G., 2010. Planetary surface dating from crater sizefrequency distribution measurements: partial resurfacing events and statistical age uncertainty. Earth Planet. Sci. Lett. 294, 223-229, http://dx.doi.org/10.1016/ j.epsl.2009.12.041.

Michalski, J.R., Cuadros, J., Niles, P.B., Parnell, J., Rogers, D.A., Wright, S.P., 2013. Groundwater activity on Mars and implications for a deep biosphere. Nat. Geosci. 6 (2), 133-138, http://dx.doi.org/10.1038/ngeo1706.

Milliken, R.E., Mustard, J.F., Goldsby, D.L., 2003. Viscous flow features on the surface of Mars: observations from high-resolution Mars Orbiter Camera (MOC) images. J. Geophys. Res. 108, 5057. 
Milliken, R.E., et al., 2008. Opaline silica in young deposits on Mars. Geology 36, 847-850, http://dx.doi.org/10.1130/G24967A.1.

Milliken, R.E., Bish, D.L., Bristow, T., Mustard, J.F., 2010. The case for mixed-layered clays on Mars. Paper Presented at Lunar and Planetary Institute Science Conference Abstracts, March 1, 2010.

Möhlmann, D., Thomsen, K., 2011. Properties of cryobrines on Mars. Icarus 212, 123-130, http://dx.doi.org/10.1016/j.icarus.2010.11.025.

Moore, J.M., Howard, A.D., Dietrich, W.E., Schenk, P.M., 2003. Martian layered fluvial deposits: implications for Noachian climate scenarios. Geophys. Res. Lett. 30 (24), 2292, http://dx.doi.org/10.1029/2003gl019002.

Morgan, G.A., Head, J.W., 2009. Sinton crater, Mars: evidence for impact into a plateau icefield and melting to produce valley networks at the HesperianAmazonian boundary. Icarus 202 (1), 39-59, http://dx.doi.org/10.1016/j. icarus.2009.02.025.

Morgenstern, A., Hauber, E., Reiss, D., van Gasselt, S., Grosse, G., Schirrmeister, L., 2007. Deposition and degradation of a volatile-rich layer in Utopia Planitia and implications for climate history on Mars. J. Geophys. Res. (Planets) 112, 6010, http://dx.doi.org/10.1029/2006JE002869.

Mouginot, J., Pommerol, A., Beck, P., Kofman, W., Clifford, S.M., 2012. Dielectric map of the Martian northern hemisphere and the nature of plain filling materials. Geophys. Res. Lett. 39, 2202, http://dx.doi.org/10.1029/2011GL050286.

Murchie, S., et al., 2009. Evidence for the origin of layered deposits in Candor Chasma, Mars, from mineral composition and hydrologic modeling. J. Geophys. Res. (Planets) 114, E00D05, http://dx.doi.org/10.1029/2009JE003343.

Musiol, S., Cailleau, B., Platz, T., Kneissl, T., Dumke, A., Neukum, G., 2011. Outflow activity near Hadriaca Patera, Mars: fluid-tectonic interaction investigated with high resolution stereo camera stereo data and finite element modeling. J. Geophys. Res. (Planets) 116, 08001, http://dx.doi.org/10.1029/2010JE003791.

Mustard, J.F., Cooper, C.D., Rifkin, M.K., 2001. Evidence for recent climate change on Mars from the identification of youthful near-surface ground ice. Nature 412, $411-414$.

Mustard, J.F., et al., 2008. Hydrated silicate minerals on Mars observed by the Mars Reconnaissance Orbiter CRISM instrument. Nature 454, 305-309.

Mustard, J.F., Ehlmann, B.L., Murchie, S.L., Poulet, F., Mangold, N., Head, J.W., Bibring, J.-P., Roach, L.H., 2009. Composition, morphology, and stratigraphy of Noachian crust around the Isidis basin. J. Geophys. Res. (Planets) 114, E00D12, http://dx. doi.org/10.1029/2009JE003349.

Nedell, S.S., Squyres, S.W., Andersen, D.W., 1987. Origin and evolution of the layered deposits in the Valles Marineris, Mars. Icarus 70 (3), 409-441, http://dx.doi.org/ 10.1016/0019-1035(87)90086-8.

Neukum, G., Basilevsky, A.T., Kneissl, T., Chapman, M.G., van Gasselt, S., Michael, G. Jaumann, R., Hoffmann, H., Lanz, J.K., 2010. The geologic evolution of Mars: episodicity of resurfacing events and ages from cratering analysis of image data and correlation with radiometric ages of Martian meteorites. Earth Planet. Sci. Lett. 294, 204-222, http://dx.doi.org/10.1016/j.epsl.2009.09.006.

Niles, P.B., Michalski, J.R., 2009. Meridiani Planum sediments on Mars formed through weathering in massive ice deposits. Nat. Geosci. 2, 215-220.

Noe Dobrea, E.Z., Poulet, F., Malin, M.C., 2008. Correlations between hematite and sulfates in the chaotic terrain east of Valles Marineris. Icarus 193, 516-534, http://dx.doi.org/10.1016/j.icarus.2007.06.029.

Noe Dobrea, E. Z., Swayze, G., 2010, Acid Pedogenesis on Mars? Evidence for TopDown Alteration on Mars from CRISM and HiRISE Data, in Lunar and Planetary Institute Science Conference Abstracts, p. 2620.

Ori, G.G., Marinangeli, L., Baliva, A., 2000. Terraces and Gilbert-type deltas in crater lakes in Ismenius Lacus and Memnonia (Mars). J. Geophys. Res. 105, 17629-17642.

Osinski, G.R., et al., 2013. Impact-generated hydrothermal systems on Earth and Mars. Icarus 224 (2), 347-363, http://dx.doi.org/10.1016/j.icarus.2012.08.030.

Osterloo, M.M., Anderson, F.S., Hamilton, V.E., Hynek, B.M., 2010. Geologic context of proposed chloride-bearing materials on Mars. J. Geophys. Res.: Planets 115 (E10), http://dx.doi.org/10.1029/2010je003613.

Parker, T.J., Saunders, R.S., Schneeberger, D.M., 1989. Transitional morphology in West Deuteronilus Mensae, Mars: implications for modification of the lowland/ upland boundary. Icarus 82 (1), 111-145, http://dx.doi.org/10.1016/0019-1035 (89)90027-4.

Parker, T.J., Gorsline, D.S., Saunders, R.S., Pieri, D.C., Schneeberger, D.M., 1993. Coastal geomorphology of the Martian northern plains. J. Geophys. Res. 98, 11061, http://dx.doi.org/10.1029/93JE00618.

Parker, T.J., Calef, F.J., 2012. Digital global map of potential ocean paleoshorelines on Mars. LPI Contributions 1680, 7085.

Petau, A., Tirsch, D., Jaumann, J., 2012a. Geomorphological analysis of mass balances of Martian valley networks in Western Terra Sirenum. In: Proceedings of Lunar and Planetary Institute Science Conference Abstracts (edited), p. 1834.

Petau, A., Tirsch, D., Jaumann, R., 2012b. Geomorphological study of fluvial environments in Terra Sirenum, Mars. In: EPSC 2012 (edited), Madrid, Spanien.

Peterson, C.M., 1981. Hebes Chasma - Martian Pyroclastic Sink. In: Proceedings of Lunar and Planetary Institute Science Conference Abstracts (edited), pp. 828-829.

Phillips, R.J., et al., 2001. Ancient geodynamics and global-scale hydrology on Mars. Science 291 (5513), 2587-2591, http://dx.doi.org/10.1126/science.1058701.

Pollack, J.B., Kasting, J.F., Richardson, S.M., Poliakov, K., 1987. The case for a wet, warm climate on early Mars. Icarus 71, 203-224.

Pondrelli, M., Baliva, A., Di Lorenzo, S., Marinangeli, L., Rossi, A.P., 2005. Complex evolution of paleolacustrine systems on Mars: an example from the Holden crater. J. Geophys. Res. (Planets) 110, 04016.

Pondrelli, M., Rossi, A.P., Marinangeli, L., Hauber, E., Gwinner, K., Baliva, A., di Lorenzo, S., 2008. Evolution and depositional environments of the Eberswalde fan delta, Mars. Icarus 197, 429-451.
Poulet, F., Bibring, J.P., Mustard, J.F., Gendrin, A., Mangold, N., Langevin, Y., Arvidson, R.E., Gondet, B., Gomez, C., 2005a. Phyllosilicates on Mars and implications for early Martian climate. Nature 438, 623-627, http://dx.doi.org/10.1038/ nature 04274.

Poulet, F., et al., 2005b. Evidence for phyllosilicates in the early Mars crust at Nili Fossae and Mawrth valles using OMEGA and HRSC Data. In: Proceedings of AGU Fall Meeting Abstracts, vol. 21, p. 0144.

Raack, J., Reiss, D., Hiesinger, H., 2012. Gullies and their relationships to the dust-ice mantle in the northwestern Argyre Basin, Mars. Icarus 219, 129-141, http://dx. doi.org/10.1016/j.icarus.2012.02.025.

Reiss, D., Van Gasselt, S., Neukum, G., Jaumann, J., 2004. Absolute dune ages and implications for the time of formation of gullies in Nirgal Vallis, Mars. J. Geophys. Res. 109, E06007, http://dx.doi.org/10.1029/2004JE002251.

Reiss, D., Hiesinger, H., Hauber, E., Gwinner, K., 2009. Regional differences in gully occurrence on Mars: a comparison between the Hale and Bond craters. Planet Space Sci. 57 (8-9), 958-974, http://dx.doi.org/10.1016/j.pss.2008.09.008.

Reiss, D., Erkeling, G., Bauch, K.E., Hiesinger, H., 2010. Evidence for present day gully activity on the Russell crater dune field, Mars. Geophys. Res. Lett. 37 (6), L06203, http://dx.doi.org/10.1029/2009gl042192.

Reiss, D., Hauber, E., Hiesinger, H., Jaumann, R., Trauthan, F., Preusker, F., Ulrich, M. Johnsson, A., Johansson, L., Olvmo, M., Carlsson, E., McDaniel, S., 2011 Terrestrial gullies and debris flows tracks on Svalbard as planetary analogs for Mars. In: Garry, W.B., Bleacher, J.E. (Eds.), Analogs for Planetary ExplorationGeological Survey of America Special Paper, pp. 165-175.

Roach, L.H., Mustard, J.F., Lane, M.D., Bishop, J.L., Murchie, S.L., 2010. Diagenetic haematite and sulfate assemblages in Valles Marineris. Icarus 207, 659-674, http://dx.doi.org/10.1016/j.icarus.2009.11.029.

Rossi, A.P., Neukum, G., Pondrelli, M., van Gasselt, S., Zegers, T., Hauber, E., Chicarro, A. Foing, B., 2008. Large-scale spring deposits on Mars? J. Geophys. Res. (Planets) 113, 8016, http://dx.doi.org/10.1029/2007JE003062.

Rossi, A.P., Van Gasselt, S., Pondrelli, M., Dohm, J., Hauber, E., Dumke, A., Zegers, T. Neukum, G., 2011. Evolution of Periglacial Landforms in the Ancient Mountain Range of the Thaumasia Highlands, Mars. vol. 356. Geological Society of London, Special Publications, pp. 69-85, http://dx.doi.org/10.1144/SP356.5.

Ruesch, O., Poulet, F., Vincendon, M., Bibring, J.-P., Carter, J., Erkeling, G., Gondet, B. Hiesinger, H., Ody, A., Reiss, D., 2012. Compositional investigation of the proposed chloride-bearing materials on Mars using near-infrared orbital data from OMEGA/MEx. J. Geophys. Res., 117, http://dx.doi.org/10.1029/2012je004108.

Sagan, C., Toon, O.B., Gierasch, P.J., 1973. Climatic change on Mars. Science 181 1045-1049.

Scanlon, K.E., Head, J.W., Madeleine, J.-B., Wordsworth, R.D., and Forget, F., 2013 Orographic precipitation in valley network headwaters: Constraints on the ancient Martian atmosphere. Geophysical Research Letters 40 (16), 4182-4187, http://dx.doi.org/10.1002/grl.50687.

Schon, S.C., Head, J.W., Milliken, R.E., 2009. A recent ice age on Mars: evidence for climate oscillations from regional layering in mid-latitude mantling deposits Geophys. Res. Lett. 36, 15202, http://dx.doi.org/10.1029/2009GL038554.

Schon, S.C., Head, J.W., Fassett, C.I., 2012. Recent high-latitude resurfacing by a climate-related latitude-dependent mantle: constraining age of emplacement from counts of small craters. Planet. Space Sci. 69, 49-61, http://dx.doi.org/ 10.1016/j.pss.2012.03.015.

Schubert, G., Anderson, J.D., Spohn, T., McKinnon, W.B., 2004. Interior composition, structure and dynamics of the Galilean satellites. In: Bagenal, F., Dowling, T.E. McKinnon, W.B. (Eds.), Jupiter. The Planet, Satellites and Magnetosphere, vol. 1 Cambridge University Press, Cambridge, pp. 281-306.

Schumm, S.A., 1997. Drainage density: problem of prediction and application. In Stoddart, D.R. (Ed.), Process and Form in Geomorphology. Routledge, London, pp. 15-45

Schwenzer, S.P., et al., 2012. Puncturing Mars: how impact craters interact with the Martian cryosphere. Earth Planet. Sci. Lett. 335-336, 9-17, http://dx.doi.org/ 10.1016/j.epsl.2012.04.031.

Scott, D.H., Tanaka, K.L., 1986. Geology map of the western equatorial region of Mars. USGS Miscellaneous Investigations Series Map I-1802-A, 1:15,000,000.

Séjourné, A., Costard, F., Gargani, J., Soare, R.J., Fedorov, A., Marmo, C., 2011. Scalloped depressions and small-sized polygons in western Utopia Planitia, Mars: a new formation hypothesis. Planet. Space Sci. 59, 412-422.

Sharp, R.P., Malin, M.C., 1975. Channels on Mars. Geol. Soc. Am. Bull. 86, 593-609.

Sizemore, H.G., Zent, A.P., Rempel, A.W., 2012, Ice Lens Formation and Unfrozen Water at the Phoenix Landing Site. In: Proceedings of Lunar and Planetary Institute Science Conference Abstracts (edited), p. 2397.

Soare, R.J., Burr, D.M., Wan Bun Tseung, J.M., 2005. Possible pingos and a periglacial landscape in northwest Utopia Planitia. Icarus 174, 373-382, http://dx.doi.org 10.1016/j.icarus.2004.11.013.

Solomon, S.C., et al., 2005. New perspectives on ancient Mars. Science 307, 1214-1220, http://dx.doi.org/10.1126/science.1101812.

Sowe, M., Jaumann, R., Neukum, G., 2011. A Comparative Study of Interior Layered Deposits on Mars. vol. 356. Geological Society of London, pp. 281-300, http //dx.doi.org/10.1144/SP356.14 (special publications)

Sowe, M., Wendt, L., McGuire, P.C., Neukum, G., 2012. Hydrated minerals in the deposits of Aureum Chaos. Icarus 218 (1), 406-419, http://dx.doi.org/10.1016/j. icarus.2011.12.009.

Squyres, S.W., Kasting, J.F., 1994. Early Mars: how warm and how wet? Science 265, 744-749.

Squyres, S.W., et al., 2004. In situ evidence for an ancient aqueous environment at Meridiani Planum, Mars. Science 306, 1709-1714, http://dx.doi.org/10.1126/ science.1104559. 
Steele, A., et al., 2005. The Astrobiology Field Laboratory, Unpublished white paper, posted December 2005, by the Mars Exploration Program Analysis Group (MEPAG) at $\langle$ http://mepag.jpl.nasa.gov/reports/〉, $71 \mathrm{p}$.

Stepinski, T. F., Luo, W., 2010. Global pattern of dissection on Mars and the northern ocean hypothesis. In: Proceedings of the Lunar and Planetary Institute Science Conference Abstracts (edited), p. 1350.

Story, S., Bowen, B.B., Benison, K.C., Schulze, D.G., 2010. Authigenic phyllosilicates in modern acid saline lake sediments and implications for Mars. J. Geophys. Res. (Planets) 115, 12012, http://dx.doi.org/10.1029/2010JE003687.

Strahler, A.N., 1958. Dimensional analysis applied to fluvially eroded landforms Geol. Soc. Am. Bull. 69, 279-299.

Tanaka, K.L., Scott, D.H., Greeley, R., 1992. Global stratigraphy. In: Kiefer, H.H., Jakosky, B.M., Snyder, C.W., Matthes, M.S. (Eds.), Mars. University of Arizona Press, Tucson, London, pp. 345-382

Tanaka, K.L., 1997. Sedimentary history and mass flow structures of Chryse and Acidalia Planitiae, Mars. J. Geophys. Res. 102, 4131-4150.

Tanaka, K.L., Skinner, J.A., Hare, T.M., 2005. Geologic map of the northern plains of Mars, U.S. Geological Survey Sci. Inv. Map 28888.

Thomson, B.J., Bridges, N.T., Milliken, R., Baldridge, A., Hook, S.J., Crowley, J.K., Marion, G.M., de Souza Filho, C.R., Brown, A.J., Weitz, C.M., 2011. Constraints on the origin and evolution of the layered mound in Gale Crater, Mars using Mars Reconnaissance Orbiter data. Icarus 214, 413-432, http://dx.doi.org/10.1016/j. icarus.2011.05.002.

Titus, T.N., Kieffer, H.H., Christensen, P.R., 2003. Exposed water ice discovered near the south pole of Mars. Science 299 (5609), 1048-1051, http://dx.doi.org/ 10.1126/science.1080497.

Tornabene, L.L., Osinski, G.R., McEwen, A.S., Wray, J.J., Craig, M.A., Sapers, H.M Christensen, P.R., 2013. An impact origin for hydrated silicates on Mars: a synthesis. J. Geophys. Res.: Planets 118 (5), 994-1012, http://dx.doi.org/10.1002/ jgre.20082.

Tosca, N.J., McLennan, S.M., Lindsley, D.H., Schoonen, M.A.A., 2004. Acid-sulfate weathering of synthetic Martian basalt: the acid fog model revisited. J. Geophys. Res. (Planets) 109, 5003. doi: 1029/2003JE002218.

Ulrich, M., Morgenstern, A., Günther, F., Reiss, D., Bauch, K.E., Hauber, E., Rössler, S. Schirrmeister, L., 2010. Thermokarst in Siberian ice-rich permafrost: comparison to asymmetric scalloped depressions on Mars. J. Geophys. Res.: Planets 115 (E10), http://dx.doi.org/10.1029/2010je003640.

Ulrich, M., Hauber, E., Herzschuh, U., Härtel, S., Schirrmeister, L., 2011. Polygon pattern geomorphometry on Svalbard (Norway) and western Utopia Planitia (Mars) using high-resolution stereo remote-sensing data. Geomorphology 134 (3-4), 197-216, http://dx.doi.org/10.1016/j.geomorph.2011.07.002.

Ulrich, M., Wagner, D., Hauber, E., de Vera, J.P., Schirrmeister, L., 2012. Habitable periglacial landscapes in martian mid-latitudes. Icarus 219 (1), 345-357, http: //dx.doi.org/10.1016/j.icarus.2012.03.019.

Van Gasselt, S., Hauber, E., Rossi, A.-P., Dumke, A., Orosei, R., Neukum, G., 2011. Periglacial Geomorphology and Landscape Evolution of the Tempe Terra region, Mars. vol. 356. Geological Society of London Special Publications, pp. 43-67, http://dx.doi.org/10.1144/SP356.4
Wald, G., 1964. The origins of life. Proc. Natl. Acad. Sci. USA 52 (2), 595-611.

Warner, N. H., Sowe, M., Gupta, S., Dumke, A., and Goddard, K., 2013. Fill and spill of giant lakes in the eastern Valles Marineris region of Mars. Geology 41 (6), 675678, http://dx.doi.org/10.1130/g34172.1.

Webb, V.E., 2004. Putative shorelines in northern Arabia Terra, Mars. J. Geophys. Res. (Planets) 109, 9010, http://dx.doi.org/10.1029/2003JE002205.

Weitz, C.M., Milliken, R.E., Grant, J.A., McEwen, A.S., Williams, R.M. E., Bishop, J.L., 2008. Light-toned strata and inverted channels adjacent to Juventae and Ganges chasmata, Mars. Geophys. Res. Lett. 35, 19202, http://dx.doi.org/ 10.1029/2008GL035317.

Weitz, C.M., Milliken, R.E., Grant, J.A., McEwen, A.S., Williams, R.M. E., Bishop, J.L., Thomson, B.J., 2010. Mars Reconnaissance Orbiter observations of light-toned layered deposits and associated fluvial landforms on the plateaus adjacent to Valles Marineris. Icarus 205, 73-102, http://dx.doi.org/10.1016/j.icarus. 2009.04.017.

Wendt, L., Gross, C., Kneissl, T., Sowe, M., Combe, J.-P., Le Deit, L., McGuire, P.C., Neukum, G., 2011. Sulfates and iron oxides in Ophir Chasma, Mars, based on OMEGA and CRISM observations. Icarus 213, 86-103, http://dx.doi.org/10.1016/ j.icarus.2011.02.013.

Wendt, L., Bishop, J.L., Neukum, G., Giesen, N., 2012. Phyllosilcates in the knob fields around Ariadnes Colles on Mars: stratigraphy, mineralogy and morphology. In: Abbasi, A. Proceedings of EGU General Assembly Conference Abstracts, p. 9105.

Williams, R.M.E., et al., 2013. Curiosity's Mastcam images reveal conglomerate outcrops with water-transported pebbles. LPI Contributions no. 1719, id 1617.

Willmes, M., Reiss, D., Hiesinger, H., Zanetti, M., 2012. Surface age of the ice-dust mantle deposit in Malea Planum, Mars. Planet. Space Sci. 60, 199-206, http: //dx.doi.org/10.1016/j.pss.2011.08.006.

Wilson, L., Ghatan, G.J., Head, J.W., Mitchell, K.L., 2004. Mars outflow channels: a reappraisal of the estimation of water flow velocities from water depths, regional slopes, and channel floor properties. J. Geophys. Res. (Planets) 109, E09003, http://dx.doi.org/10.1029/2004JE002281.

Wilson, L., Head, J.W., 2004. Evidence for a massive phreatomagmatic eruption in the initial stages of formation of the Mangala Valles outflow channel, Mars. Geophys. Res. Lett. 31, 15701, http://dx.doi.org/10.1029/2004GL020322.

Wray, J.J., et al., 2011. Columbus crater and other possible groundwater-fed paleolakes of Terra Sirenum, Mars. J. Geophys. Res. (Planets) 116, 1001, http: //dx.doi.org/10.1029/2010JE003694.

Wray, J.J., Murchie, S.L., Squyres, S.W., Seelos, F.P., Tornabene, L.L., 2009, Diverse aqueous environments on ancient Mars revealed in the southern highlands, Geology, 37, 1043-1046, http://dx.doi.org/10.1130/G30331A.1.

Wyatt, M.B., Hamilton, V.E., McSween Jr, H.Y., Christensen, P.R., Taylor, L.A., 2001. Analysis of terrestrial and Martian volcanic compositions using thermal emission spectroscopy, 1. Determination of mineralogy, chemistry and classification strategies. J. Geophys. Res. 106 (E7), 14711-714732.

Zanetti, M., Hiesinger, H., Reiss, D., Hauber, E., Neukum, G., 2010. Distribution and evolution of scalloped terrain in the southern hemisphere, Mars. Icarus 206, 691-706, http://dx.doi.org/10.1016/j.icarus.2009.09.010. 